\title{
The CBP KIX domain regulates long-term memory and circadian activity
}

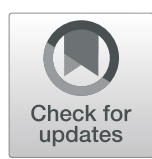

Snehajyoti Chatterjee ${ }^{1,2,3 \dagger}$, Christopher C. Angelakos ${ }^{4,5 \dagger}$, Ethan Bahl ${ }^{6,7}$, Joshua D. Hawk ${ }^{4,5}$, Marie E. Gaine ${ }^{3}$, Shane G. Poplawski ${ }^{4,5,8}$, Anne Schneider-Anthony ${ }^{1,2}$, Manish Yadav ${ }^{3}$, Giulia S. Porcari ${ }^{5}$, Jean-Christophe Cassel ${ }^{1}$, K. Peter Giese ${ }^{9}$, Jacob J. Michaelson 6,10,11,12, Lisa C. Lyons ${ }^{3,13}$, Anne-Laurence Boutillier ${ }^{1,2^{*}}$ and Ted Abel ${ }^{3^{*}}$

\begin{abstract}
Background: CREB-dependent transcription necessary for long-term memory is driven by interactions with CREBbinding protein (CBP), a multi-domain protein that binds numerous transcription factors potentially affecting expression of thousands of genes. Identifying specific domain functions for multi-domain proteins is essential to understand processes such as cognitive function and circadian clocks. We investigated the function of the CBP KIX domain in hippocampal memory and gene expression using CBP $P^{\mathrm{KI} / K I X}$ mice with mutations that prevent phosphoCREB (Ser133) binding.

Results: We found that $C B P^{K I X / K I X}$ mice were impaired in long-term memory, but not learning acquisition or shortterm memory for the Morris water maze. Using an unbiased analysis of gene expression in the dorsal hippocampus after training in the Morris water maze or contextual fear conditioning, we discovered dysregulation of CREB, CLOCK, and BMAL1 target genes and downregulation of circadian genes in $C B P^{K I X / K I X}$ mice. Given our finding that the CBP KIX domain was important for transcription of circadian genes, we profiled circadian activity and phase resetting in $\mathrm{CBP}^{\mathrm{KI} X / \mathrm{KIX}}$ mice. CBP $\mathrm{P}^{\mathrm{KI} / \mathrm{KIX}}$ mice exhibited delayed activity peaks after light offset and longer freerunning periods in constant dark. Interestingly, $\mathrm{CBP}^{\mathrm{KI} / \mathrm{KIX}}$ mice displayed phase delays and advances in response to photic stimulation comparable to wildtype littermates. Thus, this work delineates site-specific regulation of the circadian clock by a multi-domain protein.
\end{abstract}

Conclusions: These studies provide insight into the significance of the CBP KIX domain by defining targets of CBP transcriptional co-activation in memory and the role of the CBP KIX domain in vivo on circadian rhythms.

Keywords: CBP KIX domain, Spatial memory, Hippocampus, Circadian rhythm

\footnotetext{
* Correspondence: laurette@unistra.fr; ted-abel@uiowa.edu

† Snehajyoti Chatterjee and Christopher C. Angelakos contributed equally to this work.

${ }^{1}$ Laboratoire de Neuroscience Cognitives et Adaptatives (LNCA), Université de Strasbourg, Strasbourg, France

${ }^{3}$ Department of Neuroscience and Pharmacology, lowa Neuroscience

Institute, Carver College of Medicine, University of lowa, lowa City, lowa, USA

Full list of author information is available at the end of the article
}

(c) The Author(s). 2020 Open Access This article is licensed under a Creative Commons Attribution 4.0 International License, which permits use, sharing, adaptation, distribution and reproduction in any medium or format, as long as you give appropriate credit to the original author(s) and the source, provide a link to the Creative Commons licence, and indicate if changes were made. The images or other third party material in this article are included in the article's Creative Commons licence, unless indicated otherwise in a credit line to the material. If material is not included in the article's Creative Commons licence and your intended use is not permitted by statutory regulation or exceeds the permitted use, you will need to obtain permission directly from the copyright holder. To view a copy of this licence, visit http://creativecommons.org/licenses/by/4.0/ The Creative Commons Public Domain Dedication waiver (http://creativecommons.org/publicdomain/zero/1.0/) applies to the data made available in this article, unless otherwise stated in a credit line to the data. 


\section{Background}

Phosphorylation and activation of the cyclic-AMP response element-binding protein (CREB) is fundamental for the induction of gene transcription during long-term memory consolidation [1-3]. Decreased CREB levels impair spatial memory whereas overexpression of CREB in the dorsal hippocampus enhances memory [1, 4, 5]. However, CREB-induced transcription during memory formation appears tightly regulated as mice with constitutively active hippocampal CREB exhibit impairments in the retrieval of spatial memory [6]. Dysregulation of cAMP-PKA signaling and alterations in CREB activity have been associated with age-related cognitive impairments and neurodegenerative diseases [7]. In recent US National Health Surveys, more than $46 \%$ of respondents over age 65 reported memory impairments [8]. Currently, many countries around the world, including the USA, are experiencing demographic shifts towards older populations. By 2050, adults 65 and older are predicted to comprise $16 \%$ of the world's population, more than 1.5 billion individuals [9]. For neurodegenerative diseases such as Alzheimer's disease, individuals frequently experience mild cognitive impairments and memory issues years prior to disease diagnosis. Given that increased longevity increases the individual risk and societal economic burden of age-related diseases [10], there is a crucial need to understand the mechanisms and processes involved in long-term memory consolidation.

During memory consolidation, new gene expression is temporally regulated resulting in specific patterns and waves of transcription [11]. Regulation of CREB activity occurs, at least in part, in response to cAMP signaling and PKA phosphorylation of Ser-133. Following this phosphorylation, the kinase inducible domain (KID) of CREB binds to the KIX domain of the cyclic-AMP response element-binding protein (CREB) binding protein (CBP) through an induced fit mechanism [12, 13]. The interaction of phosphorylated CREB with the CBP KIX domain appears to be a specific response to cAMP-PKA signaling, and it can be modulated by external stimuli resulting in transcriptional specificity in the expression of target genes [12]. As CREB phosphorylation may also occur in response to kinases independent of cAMP-PKA signaling [14], one method through which downstream target genes in memory may be identified is through the manipulation of CREB-CBP interactions at the KIX domain. CBP is a large $265 \mathrm{kDa}$ protein containing multiple interaction domains, including the nuclear hormone receptor binding domain, transitional adapter zinc finger domains, KIX domain, bromodomain, histone acetyltransferase domain, and glutamine-rich (Q) domain. CBP interacts with numerous transcription factors to potentially regulate 16 , 000 genes [15-18]. In hippocampus-dependent memory, Cbp mutants exhibit deficiencies in contextual fear conditioning and object recognition memory [19-21]. Moreover, CBP functions as a histone acetyltransferase impacting gene expression during memory consolidation [22-27], and more specifically in memory encoding in the medial prefrontal cortex [26, 28]. In an amyloid beta model of Alzheimer's disease, restoration of CREB activity in the CA1 of the dorsal hippocampus ameliorates spatial memory deficits [29]. Similarly, pharmacological activation of $\mathrm{CBP} / \mathrm{p} 300 \mathrm{HAT}$ function improves spatial learning in wildtype (WT) mice and restores spatial long-term memory retention and hippocampal plasticity in a tauopathy mouse model [30, 31]. Decreased levels or dysregulation of CBP have been associated with neurodegenerative diseases including Huntington's Disease [32, 33] and Alzheimer's disease [34-36]. Previous research on Alzheimer's disease using rodent models found that decreases in hippocampal CBP activity levels are accompanied by decreased CREB activation, i.e., phospho-CREB levels at Ser133, although overall CREB levels were not changed [34], emphasizing the need to understand the function of CBP in transcription and memory.

As a far-reaching co-activator of transcription, CBP also regulates the endogenous circadian clock [37]. The circadian clock coordinates tissue-specific transcriptional regulation of clock-controlled genes through the core circadian transcription factors BMAL1 and CLOCK. CBP is recruited by the CLOCK/BMAL1 complex and putatively interacts with BMAL1 [38, 39]. CBP overexpression has been shown to increase CLOCK/BMAL1mediated transcription of the circadian gene period1 (per1) [40]. Despite previous identification of CBP interactions with circadian transcription factors, the role of CBP in circadian behavior has not been characterized in vivo.

In this study, we used mice expressing CBP with three point mutations in the KIX domain of CBP $\left(\mathrm{CBP}^{\mathrm{KIX} / \mathrm{KIX}}\right.$ mice), thereby preventing either phospho-CREB or cMyb binding to this region [41], to identify the downstream transcriptional pathways and targets in memory regulated by CBP KIX domain interactions, and to characterize the role of CBP KIX domain interactions on circadian activity. $\mathrm{CBP}^{\mathrm{KIX} / \mathrm{KIX}}$ mice were previously shown to present deficits in long-term memory, related to contextual fear conditioning and novel object recognition $[19,42]$; however, neither the transcriptional profile of these mice after learning nor their circadian behavior has been studied. We found that $\mathrm{CBP}^{\mathrm{KIX} / \mathrm{KIX}}$ mice exhibit specific deficits in long-term spatial memory in the Morris water maze (MWM), although no impairments were observed in these mice for task acquisition or short-term spatial memory. Given the similar memory impairments found for MWM and contextual fear conditioning, we performed deep RNA sequencing from hippocampal tissue following learning for contextual fear 
conditioning and $\mathrm{MWM}$ in $\mathrm{CBP}^{\mathrm{KIX} / \mathrm{KIX}}$ mice and $\mathrm{WT}$ littermates to identify downstream gene targets of transcriptional co-activation through the KIX domain. Pathway analysis suggested that CREB was the prominent upstream regulator of the differentially expressed genes between $\mathrm{CBP}^{\mathrm{KIX} / \mathrm{KIX}}$ mice and WT mice. Circadian clock-related genes were among the most deregulated genes after learning in the hippocampus of $\mathrm{CBP}^{\mathrm{KIX} / \mathrm{KIX}}$ mice. We characterized circadian rhythms in $\mathrm{CBP}^{\mathrm{KIX} / \mathrm{KIX}}$ mice and found that they have a lengthened freerunning circadian period compared to WT littermates. Surprisingly, the ability to phase shift activity in response to light pulses was retained in $\mathrm{CBP}^{\mathrm{KIX} / \mathrm{KIX}}$ mice. These studies provide significant insight into the role of phospho-CREB-CBP interactions in the regulation of learning-induced transcription, memory consolidation, and circadian rhythms.

\section{Results}

$\mathrm{CBP}^{\mathrm{KIX} / \mathrm{KIX}}$ mice are deficient in long-term but not shortterm spatial memory in the Morris water maze

Previously, the KIX domain of CBP, important for proteinprotein interactions $[13,43]$, was found to be essential for long-term memory after contextual fear conditioning [19] and training in the novel object recognition task [42]. However, studies have identified additional CBP functions that contribute to long-term memory including histone acetylation [30, 44]. To further characterize the specific role of the KIX domain in hippocampus-dependent longterm memory, we analyzed the consequences of a CBP KIX domain mutation on short- and long-term spatial memory using the MWM, a hippocampus-dependent task. Unlike other learning paradigms, MWM requires multiple days of training and is considered the gold standard of spatial memory tasks [45]. CBP ${ }^{\mathrm{KIX} / \mathrm{KIX}}$ mice and their WT littermates were trained over 5 consecutive days to locate a hidden platform positioned at a fixed location. Independent groups of mice were tested at separate time points to assess retention, either $1 \mathrm{~h}$ after the last training for shortterm memory or $24 \mathrm{~h}$ after training for long-term memory (Fig. 1a). Both WT and CBP ${ }^{\mathrm{KIX} / \mathrm{KIX}}$ mice showed a day-today decrease (D1 to D5) in escape latencies measured by time to the platform (Fig. 1b, Additional file 1: Fig. S1a) indicating significant learning of the task. CBP ${ }^{\mathrm{KIX} / \mathrm{KIX}}$ mice demonstrated an overall improvement throughout training similar to their WT littermates. $\mathrm{CBP}^{\mathrm{KIX} / \mathrm{KIX}}$ mice took more time to locate the platform on day 1 of training during learning acquisition, although no differences were apparent between wildtype mice and $\mathrm{CBP}^{\mathrm{KIX} / \mathrm{KIX}}$ mice on days 2,3 , and 4 of training. The impairment on day 1 is likely to be due to non-hippocampal deficits, affecting the use-of-platform learning. Therefore, we have also analyzed the distance the mice traveled to find the hidden platform across each of the training days, finding no significant difference between genotypes; thus, confirming that $\mathrm{CBP}^{\mathrm{KIX} / \mathrm{KIX}}$ mice do not display learning deficits during acquisition of the MWM task (Fig. 1c). Notably, both $\mathrm{CBP}^{\mathrm{KIX} / \mathrm{KIX}}$ and WT mice showed significant improvement in learning when performance is compared between day 1 and day 5 of training. Assessment of the average swim speed during the training days revealed a small, albeit significant, difference in the swim speed in $\mathrm{CBP}^{\mathrm{KIX} / \mathrm{KIX}}$ mice, raising the possibility that swim speed accounts for the difference in escape latencies. However, we find this possibility to be unlikely given the small difference in swim speed and the fact that we observed no significant difference between the WT and $\mathrm{CBP}^{\mathrm{KIX} / \mathrm{KIX}}$ mice during the 1-h shortterm memory recall test suggesting swim speed was not a factor in the probe test. (Additional file 1: Fig. S1b). These results suggest that $\mathrm{CBP}^{\mathrm{KIX} / \mathrm{KIX}}$ mice can improve their performance in MWM even without transcription factor interaction through the KIX domain of CBP. We assessed learning retention during the probe test by comparing the time spent in the target quadrant with time spent in the other three quadrants. During the short-term memory test (1 h) (WT, $n=10 ; \mathrm{CBP}^{\mathrm{KIX} / \mathrm{KIX}}, n=6$, Fig. 1d), WT control mice showed significant memory of the platform location with more time spent in the target quadrant compared to search time in other quadrants. Similar to WT, CBP ${ }^{\mathrm{KIX} / \mathrm{KIX}}$ mice explored significantly more in the target quadrant compared to the other three quadrants during the shortterm probe test with the search time above the chance time of $15 \mathrm{~s}$ in the target quadrant (WT, $34.9 \mathrm{~s}$, and $\mathrm{CBP}^{\mathrm{KIX} / \mathrm{KIX}}, 29.0 \mathrm{~s}$, in target quadrant) (Fig. 1d). Additionally, $\mathrm{CBP}^{\mathrm{KIX} / \mathrm{KIX}}$ and WT mice showed similar latencies of first visit to target quadrant during the short-term memory probe test (Fig. 1e). However, during the long-term memory probe test (WT, $n=10$; $\mathrm{CBP}^{\mathrm{KIX} / \mathrm{KIX}}, n=6$, probe test $24 \mathrm{~h}$, Fig. 1f), WT mice exhibited significant long-term memory with increased search time in the target quadrant over the other three quadrants (WT, $25.2 \mathrm{~s}$ vs chance $15 \mathrm{~s}$ ), while $\mathrm{CBP}^{\mathrm{KIX} / \mathrm{KIX}}$ mice searched randomly in the four quadrants reflecting the lack of long-term memory $\left(\mathrm{CBP}^{\mathrm{KIX} / \mathrm{KIX}}, 14.9 \mathrm{~s}\right.$ vs chance $\left.15 \mathrm{~s}\right)$. Similarly, $\mathrm{CBP}^{\mathrm{KIX} / \mathrm{KIX}}$ mice showed increased latencies in the first visit to the target quadrant during the long-term memory probe test (Fig. 1g). CBP ${ }^{\mathrm{KIX} / \mathrm{KIX}}$ mice did not demonstrate any sexspecific memory impairment during the short-term or long-term memory probe tests (Additional file 1: Fig. S1cd). These results indicate that $\mathrm{CBP}^{\mathrm{KIX} / \mathrm{KIX}}$ mice have deficits in long-term spatial memory consolidation, consistent with previous research on contextual memory and object location tasks [19], and suggest a crucial role for the interaction of the KIX domain with transcription factors during this process.

Hippocampus-dependent learning induces CREB phosphorylation at Ser133, a precursor event for CBP binding. Given that the $\mathrm{CBP}^{\mathrm{KIX} / \mathrm{KIX}}$ mutation prevents 

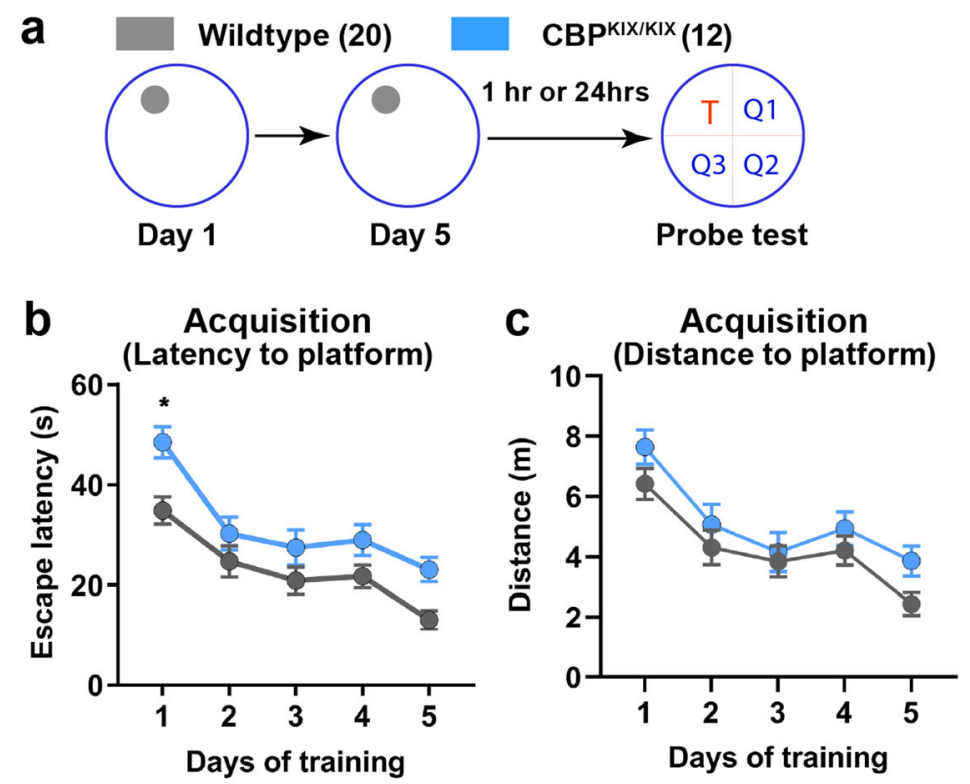

d

Short-term memory Wildtype (10) $\mathrm{CBP}^{\mathrm{KIX} / \mathrm{KIX}}(6)$

$$
\begin{aligned}
& \text { e Latency to } \\
& \text { Target quadrant }
\end{aligned}
$$
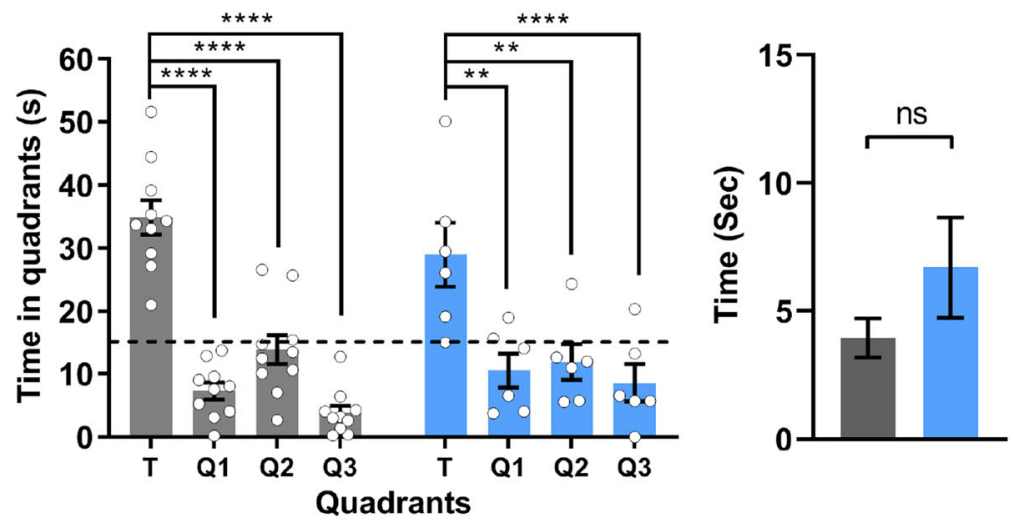

f

Long-term memory Wildtype (10) CBP ${ }^{\mathrm{KIX} / \mathrm{KIX}}(6)$
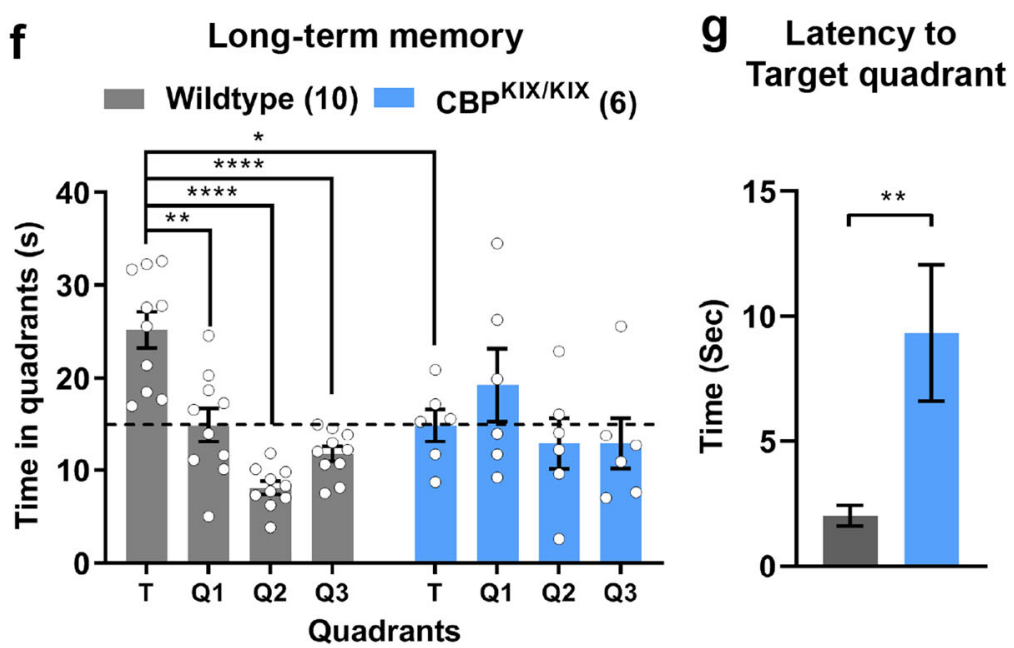

Fig. 1 (See legend on next page.) 
(See figure on previous page.)

Fig. 1 CBP ${ }^{\text {KIX/KIX }}$ mice are impaired in long-term spatial memory but have normal short-term retention. a Experimental scheme. $C B P^{K I X / K I X}(n=12)$ and WT littermates ( $n=20$, both males and females) were trained in MWM for 5 days. Short-term or long-term memory was assessed either $1 \mathrm{~h}$ or $24 \mathrm{~h}$ respectively after the last training day. $\mathbf{b}$ The acquisition curve for escape latency (time) to the platform during training indicates that $C B P^{K I X / K I X}$ mice and WT littermates learned the MWM task, finding the hidden platform more quickly on subsequent training days [Day effect, $F_{(3.429,106.3)}=20.57, p<$ 0.0001 , Day $\times$ Genotype interaction, ns]. c The acquisition curve for distance traveled to the platform during training further supports that CBP $P^{\mathrm{KI} / \mathrm{KI} X}$ mice and WT littermates learned the MWM task, finding the hidden platform more quickly on subsequent training days [Day effect, $F_{(3.465,103.9)}=13.98$, $p<0.0001$, Genotype effect, $F_{(1,30)}=5.405, P=0.0270$. Day $\times$ Genotype interaction, ns]. Sidak's multiple comparisons test: WT day 1 vs day 5: $p=0.0003$, $\mathrm{CBP} P^{\mathrm{KIX} / \mathrm{KIX}}$ day 1 vs day 5: $p=0.0006$. $\mathbf{d}$ In the 1 -h probe test for short-term memory, both CBP $\mathrm{PIX}^{\mathrm{K} / \mathrm{IX}}(n=10)$ and WT mice $(n=6)$ showed significantly higher preference for the target quadrant suggesting intact short-term retention. Bar graphs are mean \pm SEM. Two-way ANOVA revealed no interaction between "genotype" and "quadrant location" $F_{(3,42)}=1.286, p=0.2917$. Significant main effect of quadrant location was observed $F_{(3,42)}=29.07, p<$ 0.0001 , while no effect of genotype was seen $F_{(1,14)}=1.000, p=0.3343$. Sidak multiple comparisons revealed no significant difference between WT and $C B P^{K I X / K I X}$ mice in the time spent in target quadrant. e $C B P^{K I X / K I X}$ and WT mice showed similar latency in the first visit to the target quadrant during $1-\mathrm{h}$ probe test suggesting intact short-term memory $\mathbf{f} I n$ the $24-h$ probe test, $C B P^{K I X / K I X}$ mice $(n=6)$ were impaired in long-term memory as shown by reduced exploration in the target quadrant compared to WT littermates $(n=10)$. 2-way ANOVA revealed significant interaction between "genotype" and "quadrant location" $F_{(3,42)}=4.476, p=0.0082$ and a main effect of quadrant location $F_{(3,42)}=6.835, p=0.0007$. Importantly, Sidak multiple comparisons revealed a significant difference in time in target platform between WT and CBP KIX/KIX mice (adjusted $p=0.0030$ ). Data are presented as mean \pm SEM. Differences are significant at ${ }^{*} p<0.05,{ }^{* *} p<0.01,{ }^{* * *} p<0.001$, evaluated with two-way ANOVA and Sidak multiple correction. TQ, target quadrant; Q1, Q2, Q3 correspond to the three other quadrants. $\mathbf{g}$ CBP $P^{\mathrm{KI} / \mathrm{KIX}}$ mice showed significantly higher latency of first visit to target quadrant during 24-h probe test suggesting impaired long-term memory. Unpaired $t$ test, $p=0.0040$

phospho-CREB (Ser133) binding to CBP, we hypothesized that phospho-CREB (Ser133) levels would be decreased in $\mathrm{CBP}^{\mathrm{KIX} / \mathrm{KIX}}$ mice as the CREB protein would be more vulnerable to phosphatase activity at the Ser133 site. To test this hypothesis, we performed western blots of protein extracted from WT and $\mathrm{CBP}^{\mathrm{KIX} / \mathrm{KIX}}$ mice $1 \mathrm{~h}$ after the third day of MWM training. As expected, we found that MWM increased CREB phosphorylation at Ser133 in WT mice. Phospho-CREB levels were reduced in $\mathrm{CBP}^{\mathrm{KIX} / \mathrm{KIX}}$ mice after training compared to WT mice, although no differences in the baseline levels of CREB phosphorylation at Ser133 were observed in homecage controls (Additional file 1: Fig. S2).

\section{CBP KIX domain mutation alters circadian gene expression in the dorsal hippocampus following spatial learning}

As CBP can bind either CREB or c-MYB through the KIX domain [13, 46, 47], we wanted to identify the set of genes for which KIX domain transcription factor binding is necessary to enable hippocampus-dependent memory consolidation. Consequently, we performed an unbiased analysis of gene expression using deep RNA sequencing of dorsal hippocampal tissues from $\mathrm{CBP}^{\mathrm{KIX} / \mathrm{KIX}}$ mice and WT littermates after training in the MWM (RNA-Seq 1) or contextual fear conditioning (RNA-Seq 2) (Fig. 2a). Spatial memory has been shown to be dependent upon the dorsal, but not ventral, hippocampus [48-51]. As the objective was to identify gene expression common to multiple types of hippocampus-dependent memory consolidation, we analyzed the data together from RNA-Seq 1 and RNA-Seq 2. We tested for differences in expression between $\mathrm{WT}$ and $\mathrm{CBP}^{\mathrm{KIX} / \mathrm{KIX}}$ mice, using experimental batch (i.e., RNA-Seq 1/RNA-Seq 2) as a covariate to delineate genes dysregulated by the KIX domain across multiple paradigms of hippocampus-dependent learning. We identified 158 differentially expressed genes (DEGs) at a false discovery rate (FDR) of 0.05 (Fig. 2b). Among the DEGs, 114 genes were downregulated while 44 were upregulated in $\mathrm{CBP}^{\mathrm{KIX} / \mathrm{KIX}}$ mice relative to WT (Additional file 2: Table S1). As CBP positively regulates transcription [52], we hypothesized that the downregulated genes in $\mathrm{CBP}^{\mathrm{KIX} / \mathrm{KIX}}$ mice may have a more direct impact on memory formation. Utilizing enrichment network analysis after annotating the downregulated DEGs through the Kyoto Encyclopedia of Genes and Genomes (KEGG) pathway database, we found the downregulated DEGs to be most significantly enriched for genes in the mammalian circadian rhythm pathway (Fig. 2c), thus specifically linking the KIX domain of CBP to the regulation of circadian gene transcription and expanding upon previous research establishing interactions between CBP and the circadian transcriptional heterodimer CLOCK-BMAL1 [38, 40, 53, 54]. We found that the most significantly upregulated pathway in $\mathrm{CBP}^{\mathrm{KIX} / \mathrm{KIX}}$ mice was the cell adhesion molecule pathway.

To identify the transcriptional drivers of DEGs in $\mathrm{CBP}^{\mathrm{KIX} / \mathrm{KIX}}$ mice in an unbiased fashion, we used QIAG EN's Ingenuity Pathway Analysis (IPA). From our observed DEGs, upstream regulator analysis in IPA identified CREB1 as the top predicted upstream regulator of DEGs between $\mathrm{CBP}^{\mathrm{KIX} / \mathrm{KIX}}$ and WT after learning (activation $z$-score $=-3.349$ ) (Fig. 2d, Additional file 2: Table S2). Sixteen downregulated and six upregulated genes among the DEGs were found to be regulated by CREB (Fig. 2e). The second most significant upstream regulator of DEGs was CLOCK (activation $z$-score $=-2.927$ ). BMAL1 (also known as ARNTL), a binding partner of CLOCK, also ranked highly as a significant upstream regulator of DEGs (activation $z$-score $=-2.192$ ). Among 


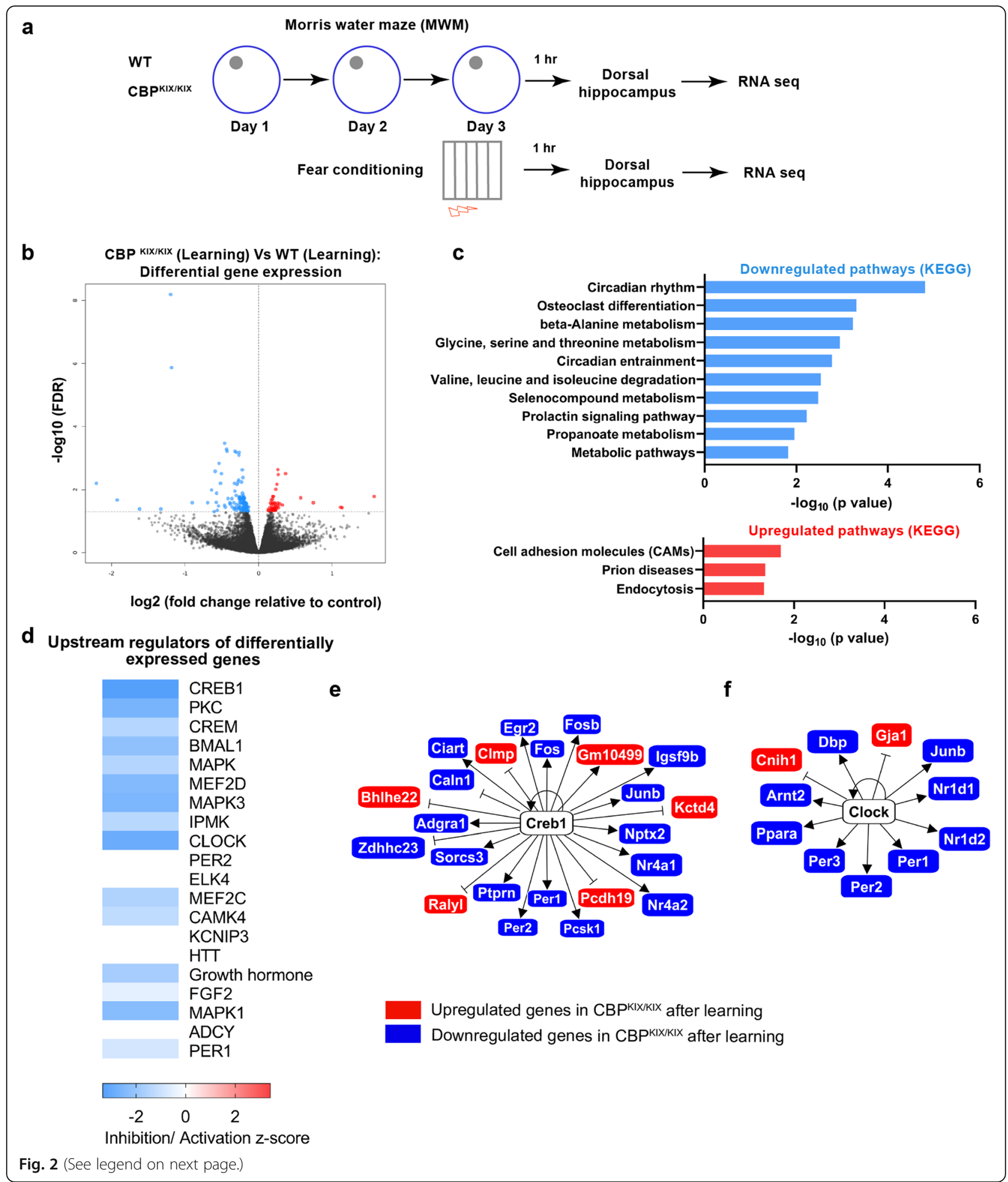


(See figure on previous page.)

Fig. 2 Differential gene expression analysis in the dorsal hippocampus of CBP ${ }^{\mathrm{KI} / \mathrm{KIX}}$ mice following spatial learning. a Experimental scheme: Total RNA was extracted from the dorsal hippocampus of $\mathrm{CBP}^{\mathrm{KI} / \mathrm{KIX}}$ and control littermates $1 \mathrm{~h}$ after MWM training (day 3, trial 4) and $1 \mathrm{~h}$ after contextual fear conditioning ( $n=7 \mathrm{CBP}{ }^{\mathrm{KI} / \mathrm{KIX}}, n=7$ controls). Each set of experiments was sequenced separately but analyzed together to identify common genes responsive to hippocampus-dependent learning. $\mathbf{b}$ Volcano plot illustrating differentially expressed genes between CBP ${ }^{\mathrm{KI} / \mathrm{KIX}}$ and control mice after learning (common between MWM and contextual fear conditioning). c KEGG pathway enrichment network analysis showing significant KEGG pathways enriched in the downregulated genes. Top significant pathways are shown in the bar graph. Mammalian circadian rhythm pathway $\left(p=1.55 \times 10^{-5}\right)$. $\mathbf{d}$ Heat map of IPA upstream regulator analysis on differentially expressed genes in $\mathrm{CBP} \mathrm{K}^{\mathrm{KI} / \mathrm{KI}}$ mice following training. Most significant regulators are on the top of the heat map. CREB1, also known as CREB, is the top-predicted upstream regulator of differentially expressed genes (FDR $<0.05)$ in the $\mathrm{CBP}^{\mathrm{KI} / \mathrm{KIX}}$ mice compared to wildtype littermates (predicted inhibition, $z$-score $=-3.349, p=1.49 \times 10^{-14}$. e, $\mathbf{f}$ Known interactions of differentially expressed genes $(F D R<0.05)$ in CBP ${ }^{\mathrm{KI} / \mathrm{KIX}}$ vs control following learning predicting CREB1 (e) and CLOCK $(\mathbf{f})$ as upstream regulators

the CLOCK-regulated genes, we identified genes related to circadian rhythm including $N r 1 d 1, N r 1 d 2$, Per1, Per2, Per3, and Dbp (Fig. 2f).

\section{Spatial learning induces CBP downstream genes in WT mice}

Following our finding that circadian and activitydependent genes were downregulated after learning in $\mathrm{CBP}^{\mathrm{KIX} / \mathrm{KIX}}$ mice, relative to WT mice, we next analyzed gene expression profiles of hippocampus-dependent learning by comparing the WT learning group from both tasks (contextual fear conditioning and MWM) to the WT homecage controls (Experimental Schematic Fig. 3a). We identified 135 DEGs at an FDR of 0.05 (Fig. 3b). Among the DEGs, 47 genes were downregulated while 88 were upregulated following learning (Additional file 2: Table S3). To externally validate our results, we tested the list of learning-responsive genes for enrichment of genes previously identified as differentially expressed $1 \mathrm{~h}$ following in vivo chemically induced neuronal activation [55]. We found a significant enrichment of these positive controls $(P=1.035 \mathrm{e}-10$, odds ratio $=3.57$; Additional file 2: Table S4), suggesting that transcriptional programs reproducibly regulated by learning in multiple behavioral paradigms share significant overlap with genes regulated by in vivo chemical activation of neurons.

Using enrichment network analysis after annotating the upregulated DEGs through the KEGG pathway database, we found that the most significant change occurred in the MAPK signaling pathway (also known as the Ras-RafMEK-ERK pathway) (Fig. 3c). Circadian genes have recently been shown to be involved in hippocampusdependent memory [56, 57], and the lack of functional Per1 in the hippocampus impairs object location memory [58] and LTP [59]. As predicted, based upon the downregulation of circadian pathways we observed after learning in $\mathrm{CBP}^{\mathrm{KIX} / \mathrm{KIX}}$ mice, we also found pathways related to circadian rhythm and circadian entrainment to be upregulated following spatial learning in WT mice. Analysis of the most significantly downregulated pathways revealed that genes associated with cellular senescence were the most significantly downregulated genes after learning, consistent with the hypothesis that learning increases neuronal survival with neurogenesis [60-62].

Upstream regulator analysis revealed cAMP-PKA responsive transcription factor CREM and CREB to be the top upstream regulators of the DEGs predicted to be activated following learning (Fig. 3d, Additional file 2: Table S5). CREM can be activated through phosphorylation at Ser 117 as well as independently activated in some tissues [63]. CREB target genes included 19 upregulated and one downregulated gene (Fig. 3e), while CREM regulated genes included 18 upregulated genes following learning in WT mice (Fig. 3f). Interestingly, we found several genes regulated by both CREB and CREM to be upregulated following learning in WT mice and otherwise downregulated in $\mathrm{CBP}^{\mathrm{KIX} / \mathrm{KIX}}$ mice (Figs. 3e, $\mathrm{f}$ and $2 \mathrm{e}, \mathrm{f}$ ).

\section{Comparisons of differential gene expression in hippocampus-dependent learning paradigms reflect genes dysregulated after learning in $\mathrm{CBP}^{\mathrm{KIX} / \mathrm{KIX}}$ mice}

To integrate the results of the preceding RNA-Seq experiments and to determine whether the learningresponsive genes (MWM and contextual fear conditioning) in WT mice were dysregulated after learning in $\mathrm{CBP}^{\mathrm{KIX} / \mathrm{KIX}}$ mice, we tested whether the genes differentially expressed in $\mathrm{CBP}^{\mathrm{KIX} / \mathrm{KIX}}$ mice following learning were significantly enriched for genes differentially expressed following learning in WT animals compared to the homecage condition. We found a significant enrichment $(P=5.91 \mathrm{e}-10$, odds ratio $=13.51)$, suggesting that inhibition of protein interactions through the CBP KIX binding following learning prevents hippocampal learning-regulated transcription. Heat map representations were made based on the twelve most significant DEGs common across data sets (Fig. 4a). Consistent with our previous analysis, circadian genes were among the most significant genes differentially expressed across data sets with Per1 and Per2 in the top upregulated genes in WT mice with learning and downregulated in $\mathrm{CBP}^{\mathrm{KIX} / \mathrm{KIX}}$ mice (Fig. 4a-b). Not surprisingly, activitydependent genes including Junb, Fosb, and Nr4a1 were significantly upregulated after learning in WT mice and significantly downregulated in $\mathrm{CBP}^{\mathrm{KIX} / \mathrm{KIX}}$ mice after 


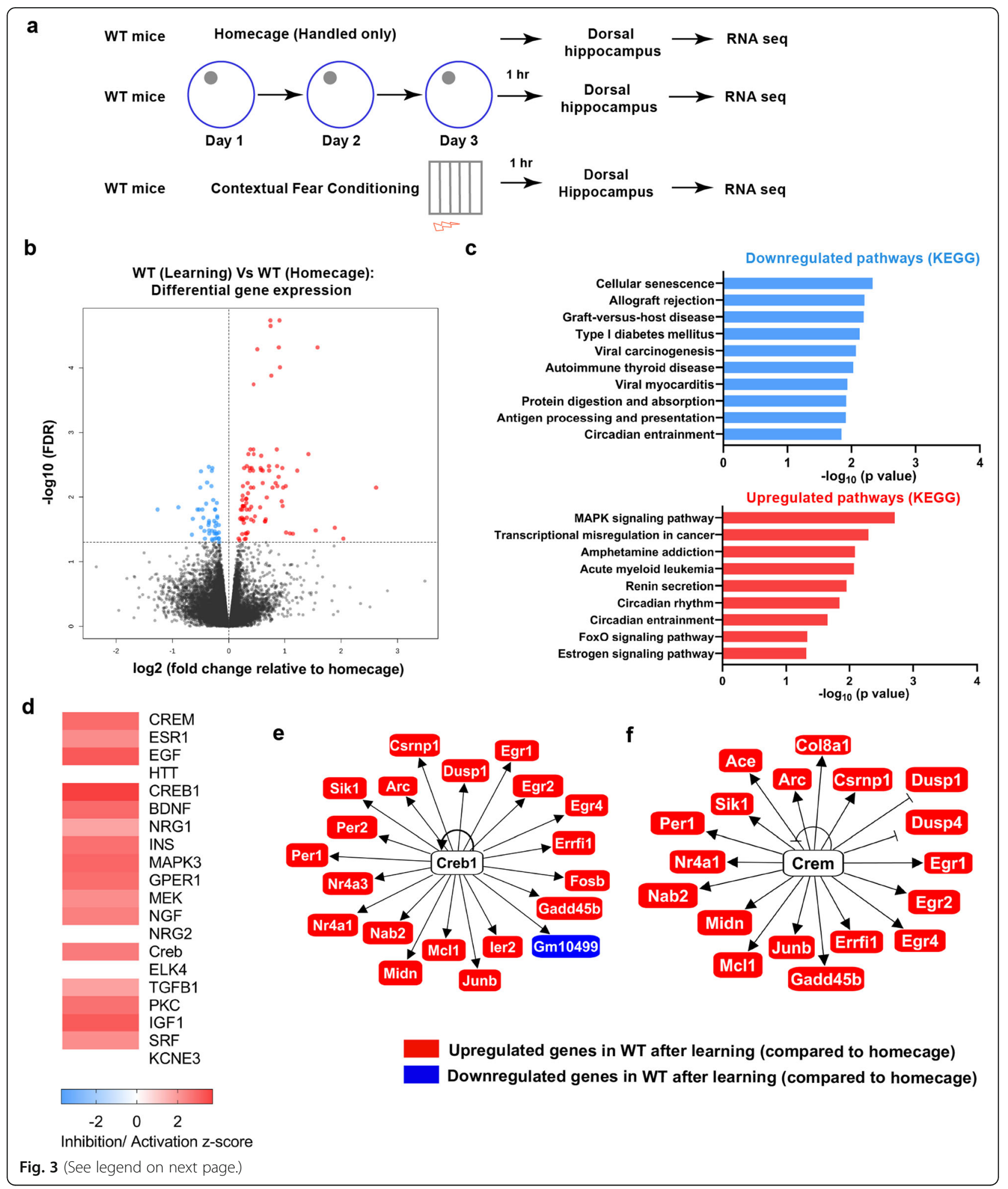


(See figure on previous page.)

Fig. 3 Differential gene expression analysis in the dorsal hippocampus of wildtype mice following learning in fear conditioning and water maze compared to homecage controls. a Experimental scheme: RNA-Seq analysis performed after learning in Fig. 2 was compared to RNA extracted from WT homecage animals. To identify the genes altered by learning, we compared WT contextual fear conditioning $(n=4)$ with WT homecage $(n=4)$ and WT MWM $(n=3)$ with WT homecage $(n=3)$. b Volcano plot illustrating differentially expressed genes between WT learning and WT homecage mice. c KEGG pathway enrichment network analysis showing significant KEGG pathways enriched in the upregulated genes. Top significant pathways are shown in the bar graph. MAPK signaling pathway $(p=0.0019)$. $\mathbf{d}$ Heat map of IPA upstream regulator analysis on differentially expressed genes in $C B P^{K I X / K I X}$ mice following training. Most significant regulators are on the top of the heat map. CREM is the top-predicted upstream regulator of differentially expressed genes (FDR $<0.05$ ) in the WT learning group compared to homecage controls (predicted activation, $z$-score $=2.854, p=2.54 \times$ $10^{-21}$ ). CREB1 also appears as an upstream regulator (predicted activation, $z$-score $=3.715, p=3.97 \times 10^{-13}$ ). e, $\mathbf{f}$ Known interactions of differentially expressed genes $(F D R<0.05)$ in learning group vs homecage predicting CREB $(\mathbf{e})$ and CREM $(\mathbf{f})$ as upstream regulators

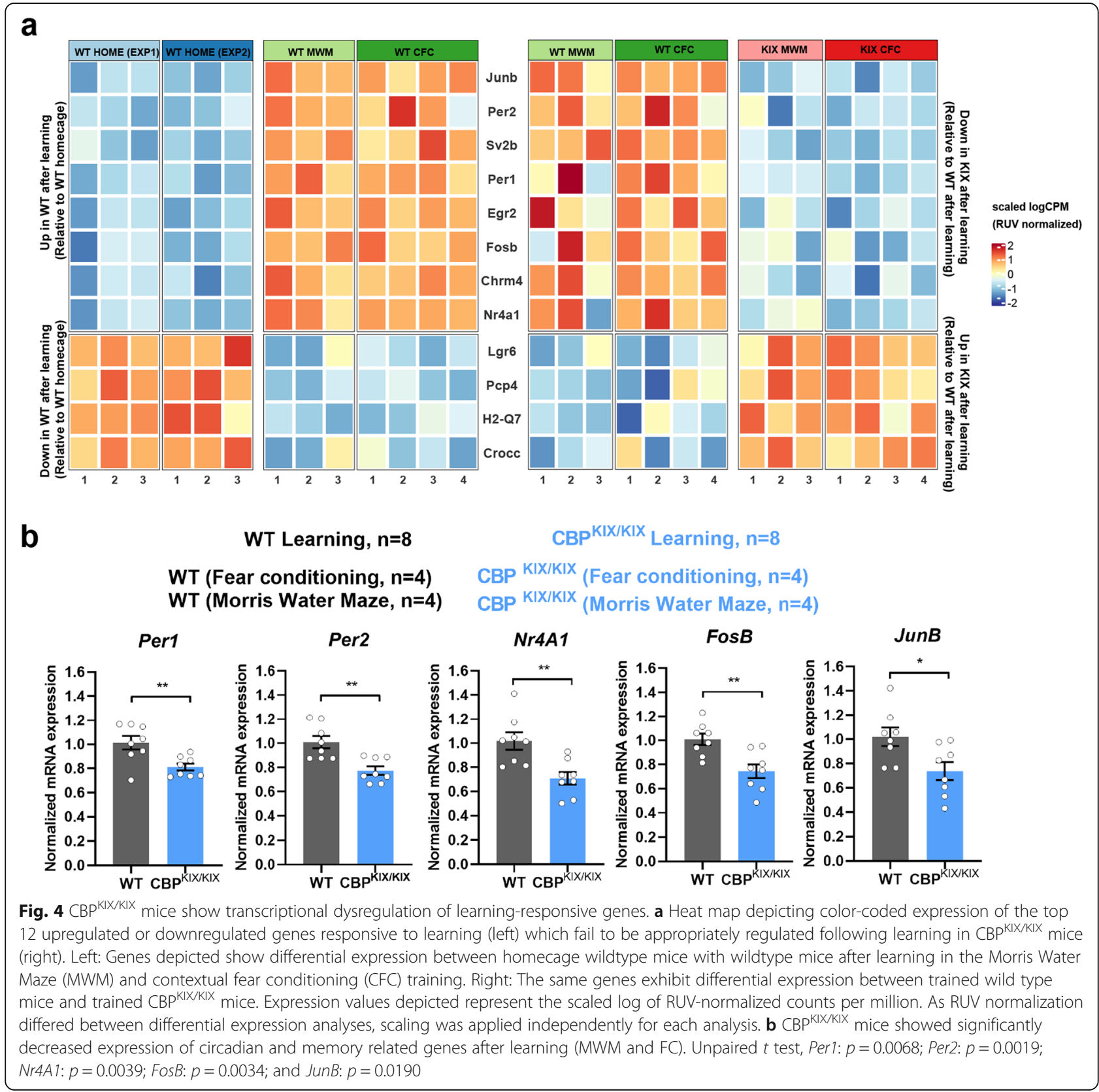


learning (Fig. 4a, b). Sv2b, a synaptic vesicle protein important in vesicle secretion and neurotransmission, was also significantly upregulated in WT mice after learning compared to homecage animals and downregulated in $\mathrm{CBP}^{\mathrm{KIX} / \mathrm{KIX}}$ mice after learning compared to WT mice. Analysis across data sets identified Pcp4 (Purkinje cell protein 4), a calmodulin-binding protein that acts as a modulator of calcium signaling, as significantly downregulated in WT mice after learning and upregulated in $\mathrm{CBP}^{\mathrm{KIX} / \mathrm{KIX}}$ mice after learning suggesting dysregulated intracellular signaling in $\mathrm{CBP}^{\mathrm{KIX} / \mathrm{KIX}}$ mice after learning. We further assessed the overlap between genes regulated by learning in WT mice and genes regulated in $\mathrm{CBP}^{\mathrm{KIX} /-}$ KIX mice following learning using the rank-rank hypergeometric overlap approach to identify common gene signatures (Additional file 1: Fig. S3a). Maximal enrichment of 53 common genes between lists was observed when considering the top 500 genes from each list, corresponding to FDR thresholds of 0.146 for genes regulated by learning, and 0.133 for genes regulated by KIX following learning, suggesting additional biological signal may lie outside the FDR $\leq 0.05$ threshold in which 12 common genes were identified. We compared enrichment of gene ontology terms using standard FDR thresholds of 0.05 , with the aforementioned thresholds supporting maximal RRHO enrichment. As thresholds were relaxed, several terms showed diminished significance such as entrainment of circadian clock and cellular response to hormone stimulus, suggesting those biological signals were primarily derived from significant genes at FDR $\leq 0.05$. We also found that several additional terms were significant, including nuclear receptor activity and postsynaptic density membrane localization (Additional file 2: Fig. S3b).

\section{The CBP KIX mutation has only a modest effect on baseline gene expression}

In the $\mathrm{CBP}^{\mathrm{KIX} / \mathrm{KIX}}$ mutant mice, it is possible that developmental consequences of the mutation affect gene expression in the hippocampus in such a manner that neural circuitry or basal synaptic transmission would be affected. Although this possibility appears less likely given previous research with these mice in contextual fear conditioning [19] and our behavioral data in the MWM task in which $\mathrm{CBP}^{\mathrm{KIX} / \mathrm{KIX}}$ mice demonstrated task acquisition and short-term memory retention similar to WT mice, we analyzed baseline gene expression in $\mathrm{WT}$ and $\mathrm{CBP}^{\mathrm{KIX} / \mathrm{KIX}}$ mice. We performed microarray gene expression analysis using Affymetrix MOE 430v2 arrays in WT and CBP ${ }^{\mathrm{KIX} / \mathrm{KIX}}$ mice, using RNA extracted from whole hippocampus. We found comparatively few changes in gene expression in $\mathrm{CBP}^{\mathrm{KIX} / \mathrm{KIX}}$ mutant mice in baseline/ homecage conditions with almost all of the observed downregulation of gene expression consistent with the function of CBP as a positive regulator of gene expression (Table 1). Among the 27 downregulated genes and one upregulated gene that were differentially regulated in the homecage condition between WT and $\mathrm{CBP}^{\mathrm{KIX} / \mathrm{KIX}}$ mice (95\% confidence level), Fos was the only activity-dependent gene downregulated in $\mathrm{CBP}^{\mathrm{KIX} / \mathrm{KIX}}$ mice. Even when the confidence level was reduced to $80 \%$, only 63 genes were found to be downregulated in the mutant mice and three upregulated (Additional file 2: Table S6). Overall, most of the observed gene changes were modest reductions in gene expression (average 23\% reduction). The observation of differential expression in such a limited number of genes under homecage conditions is likely a result of the specificity of the KIX mutation as it affects only a single interaction interface of the protein [47]. Although unlikely, it is possible that the KIX mutation affected stability of the mRNA encoding CBP. Using three non-overlapping probes, our microarray data confirmed that overall RNA levels for $\mathrm{CBP}$ were not reduced in the mutant mice compared to WT mice. The KIX mutation was validated using a fourth $\mathrm{CBP}$ probe set that hybridizes with the region containing the mutated base pairs in the $\mathrm{CBP}^{\mathrm{KIX} / \mathrm{KIX}}$ mice. We found that the signal was substantially reduced as predicted (Additional file 1: Fig. S4).

Although we did not find many differentially expressed genes between $\mathrm{WT}$ and $\mathrm{CBP}^{\mathrm{KIX} / \mathrm{KIX}}$ mice in homecage conditions, we wanted to confirm these results particularly for circadian genes, since we found that circadian genes were downregulated after learning in $\mathrm{CBP}^{\mathrm{KIX} / \mathrm{KIX}}$ in comparison to WT animals. To complement the results from the microarray experiments, we performed quantitative real-time PCR for eight core circadian genes to determine if there were any differences in expression between WT and $\mathrm{CBP}^{\mathrm{KIX} / \mathrm{KIX}}$ mice in homecage conditions. We found that seven of the eight genes had similar expression levels between WT and $\mathrm{CBP}^{\mathrm{KIX} / \mathrm{KIX}}$ mice, while $D b p$ exhibited significant downregulation in $\mathrm{CBP}^{\mathrm{KIX} / \mathrm{KIX}}$ mice (Additional file 1: Fig. S5). Furthermore, we performed differential expression analysis of the RNASeq data for WT and CBP ${ }^{\mathrm{KIX} / \mathrm{KIX}}$ samples the from dorsal hippocampus of homecage mice. We found that for the twelve overlapping genes regulated by learning in WT, and the KIX genotype after learning, none was significantly different between the genotypes at baseline in homecage conditions (Additional file 2: Fig. S6). Thus, it appears that the differential gene expression we observed between $\mathrm{WT}$ and $\mathrm{CBP}^{\mathrm{KIX} / \mathrm{KIX}}$ mice after training in the Morris water maze or contextual fear condition was training dependent, rather than due to differences in baseline gene expression. 
Table 1 Highest confidence (95\%) changes in homecage gene expression in CBP ${ }^{\mathrm{KIX} / \mathrm{KIX}}$ mice

\begin{tabular}{|c|c|c|c|c|c|}
\hline Gene symbol & Confidence & Probe set & Molecular role & Wt(Log2) & $\%$ change \\
\hline \multicolumn{6}{|c|}{ Downregulated genes } \\
\hline Slc25a34 & 0.995 & 1455506_at & Mitochondrial solute carrier protein & 7.99 & $-43 \%$ \\
\hline Papss2 $2^{\# \#}$ & 0.995 & 1421987_at & Sulfate Adenylyltransferase, cysteine synthesis & 6.89 & $-42 \%$ \\
\hline Efcab6 & 0.993 & 1453766_a_at & Calcium-binding transcriptional co-repressor & 8.02 & $-25 \%$ \\
\hline $\mathrm{Cbp}$ & 0.993 & 1459804_at & Transcriptional co-activator CBP, KIX domain & 8.41 & $-37 \%$ \\
\hline Nts & 0.991 & 1422860_at & Neuropeptide & 10.73 & $-31 \%$ \\
\hline Lipm $^{\#}$ & 0.991 & 1430550_at & Triglyceride hydrolysis & 5.38 & $-40 \%$ \\
\hline Cenpa & 0.991 & 1450842_a_at & Double-strand break repair, centromere organization & 6.75 & $-29 \%$ \\
\hline Pmch & 0.988 & 1429361_at & Neuropeptide & 7.33 & $-24 \%$ \\
\hline Fos & 0.988 & 1423100_at & DNA-binding transcription factor & 9.55 & $-33 \%$ \\
\hline Crhbp & 0.988 & 1436127_at & Regulator of hormone signaling & 11.03 & $-20 \%$ \\
\hline $\mathrm{Ccl}^{\#}$ & 0.988 & 1420249_s_at & Cytokine, inflammatory response & 6.79 & $-25 \%$ \\
\hline Cth & 0.987 & 1426243_at & Cysteine-Protein Sulfhydrase, cysteine synthesis & 7.89 & $-24 \%$ \\
\hline $\mathrm{Nqo} 1$ & 0.98 & 1423627_at & Positive regulator of translation; quinone detoxification & 9.27 & $-20 \%$ \\
\hline Tbx1 & 0.975 & 1425779_a_at & DNA-binding transcription factor & 5.65 & $-25 \%$ \\
\hline Spata13 & 0.975 & 1454656_at & Guanine nucleotide exchange factor & 9.44 & $-19 \%$ \\
\hline $\operatorname{Rec} 8$ & 0.975 & 1419147_at & Meiotic chromatid cohesion & 6.68 & $-26 \%$ \\
\hline Bglap & 0.972 & 1449880_s_at & Osteogenic marker & 7.13 & $-38 \%$ \\
\hline Cyp11a1 & 0.965 & 1448804_at & Steriod hormone metabolism, cholesterol metabolism & 7.43 & $-28 \%$ \\
\hline Pdlim2 & 0.962 & 1423946_at & Negative regulator of NFkappa-B and STAT signaling & 9.46 & $-21 \%$ \\
\hline Zdbf2 & 0.955 & 1456783_at & Unknown & 10.51 & $-16 \%$ \\
\hline Pcsk1 & 0.955 & 1421396_at & Pro-neuropeptide cleavage & 7.91 & $-24 \%$ \\
\hline Gpnmb & 0.955 & 1448303_at & Transmembrane glycoprotein & 7.84 & $-18 \%$ \\
\hline Dusp10 & 0.955 & 1417163_at & Phosphatase & 8.96 & $-17 \%$ \\
\hline $\mathrm{Dbp}^{\#}$ & 0.955 & 1418174_at & DNA-binding transcription factor & 10.63 & $-24 \%$ \\
\hline Plcd1 & 0.952 & 1448432_at & $\mathrm{Ca}^{+}{ }^{-}$-dependent phospholipase, phosphotidyl inositol-signaling & 8.69 & $-18 \%$ \\
\hline Mmel1 & 0.952 & 1449432_a_at & Membrane metalloprotease & 5.17 & $-28 \%$ \\
\hline Cort & 0.952 & 1449820_at & Neuropeptide & 9.01 & $-30 \%$ \\
\hline \multicolumn{6}{|c|}{ Upregulated genes } \\
\hline Ifi27|2a & 0.995 & 1427747_a_at & Interferon, alpha-inducible protein 27 like 2A & 2.19 & $358 \%$ \\
\hline
\end{tabular}

\#A second probe set for this gene was also present in the $80 \%$ confidence probe set list

\#\#Two additional probe sets for this gene were present in the $80 \%$ confidence probe set list

$\mathrm{CBP}^{\mathrm{KIX} / \mathrm{KIX}}$ mice display increased free-running period length and phase differences in peak activity compared to WT mice

Our studies indicate that the CBP KIX domain is important for regulation of gene transcription by the circadian transcription factors CLOCK and BMAL1 even though in vitro studies have suggested that CBP interactions with BMAL1 occurred in a region outside of the KIX domain in CBP [64]. We then investigated in vivo circadian rhythms in $\mathrm{CBP}^{\mathrm{KIX} / \mathrm{KIX}}$ mice. We measured homecage activity in $\mathrm{CBP}^{\mathrm{KIX} / \mathrm{KIX}}$ and WT mice using infrared beam breaks with 1 week of continuous monitoring in a 12-h light/12-h dark (12 h:12 h LD) cycle. Layered infrared beams allow quantification of locomotor activity as well as rearing, as previously described [65] (Fig. 5a). CBP ${ }^{\mathrm{KIX} / \mathrm{KIX}}$ mice had significantly lower anticipatory activity in the last hour of the light (inactive) phase and lower activity in the first $2 \mathrm{~h}$ of the dark phase. We found that $\mathrm{CBP}^{\mathrm{KIX} / \mathrm{KIX}}$ mice reached peak activity levels $3 \mathrm{~h}$ later than their WT littermates. Despite the circadian alterations in activity profiles, there was no difference between $\mathrm{CBP}^{\mathrm{KIX} / \mathrm{KIX}}$ and WT mice in total activity across the 24-h day (Fig. 5b). We also found no differences in activity when the light and dark phases were analyzed separately (Fig. 5c). We observed significant delays in activity onset and peak activity in both male and female $\mathrm{CBP}^{\mathrm{KIX} / \mathrm{KIX}}$ mice (Additional file 2: Fig. S7). These results indicate that male and female 


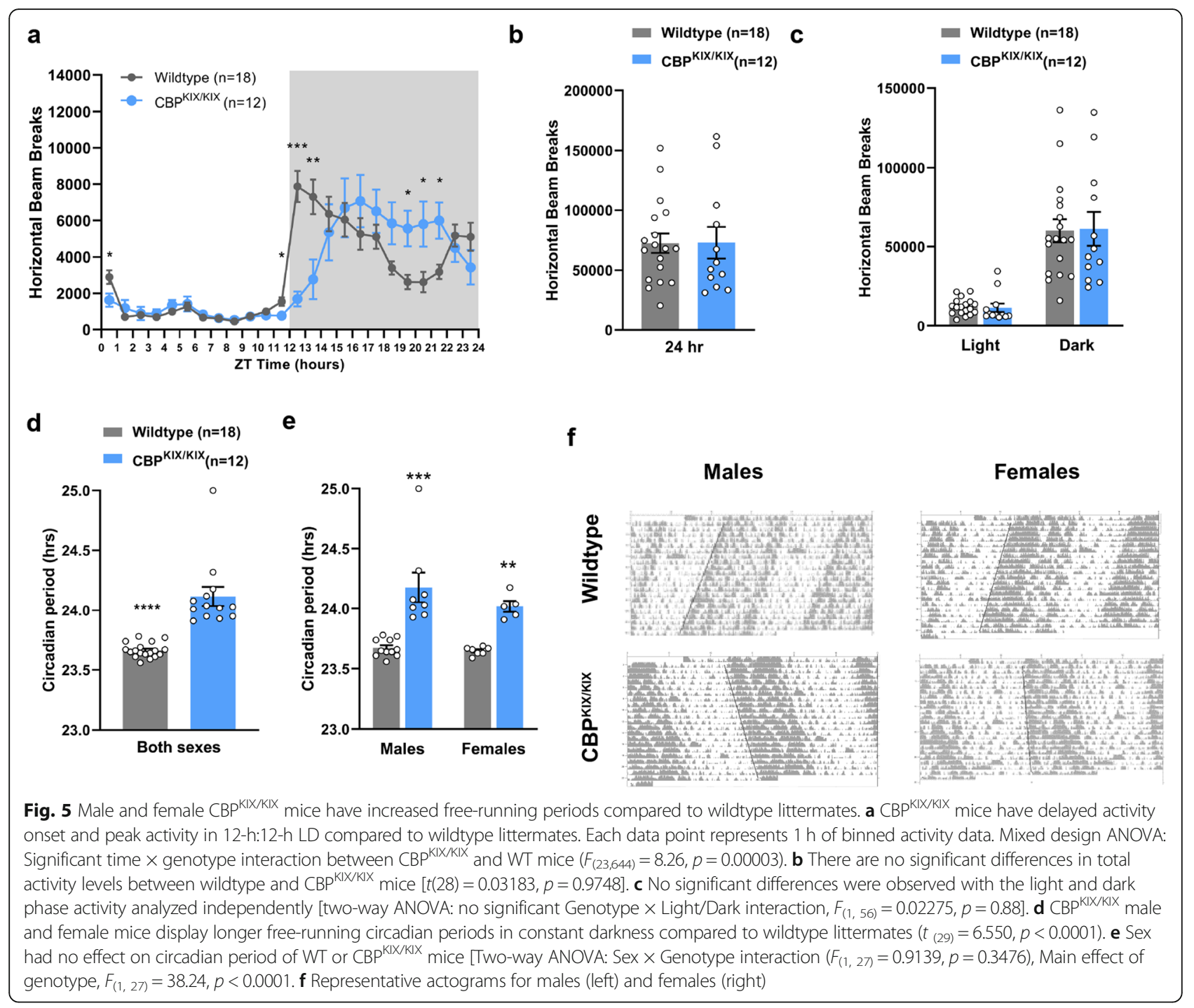

$\mathrm{CBP}^{\mathrm{KIX} / \mathrm{KIX}}$ mice have delayed activity patterns in $12-\mathrm{h}$ : 12-h LD while maintaining normal total locomotor activity levels. Given the temporally shifted activity patterns of $\mathrm{CBP}^{\mathrm{KIX} / \mathrm{KIX}}$ mice, we next investigated whether the $\mathrm{CBP}^{\mathrm{KIX} / \mathrm{KIX}}$ mutation affected free-running circadian rhythms under constant conditions. After entrainment to $\mathrm{LD}$ cycles, $\mathrm{CBP}^{\mathrm{KIX} / \mathrm{KIX}}$ and WT mice were placed in constant darkness for 4 weeks to measure circadian activity and period length. CBP ${ }^{\mathrm{KIX} / \mathrm{KIX}}$ mice had a significantly longer circadian period, $\sim 22.9 \mathrm{~min}$, than WT littermates (WT $23.66 \pm 0.01 \mathrm{~h}, \mathrm{CBP}^{\mathrm{KIX} / \mathrm{KIX}} 24.05 \pm 0.03$ h) (Fig. $5 \mathrm{~d}-\mathrm{f}$ ). There was no effect of sex on circadian period with both male and female $\mathrm{CBP}^{\mathrm{KIX} / \mathrm{KIX}}$ mice displaying significantly lengthened free-running periods. This shift in circadian period is roughly similar to the shifts observed in knockouts of core circadian clock genes, including CLOCK [66], Per1 [67], Per3 [68], Nr1d1 [69], Dbp [70], Rora [71], Rorb [72], and Npas2
[73] [summarized in [74]]. Thus, these results provide in vivo evidence that the KIX domain of CBP is an integral modulator of circadian period length and activity profiles.

To further probe the role of the KIX domain of CBP in the circadian clock, we investigated phase-shifting in $\mathrm{CBP}^{\mathrm{KIX} / \mathrm{KIX}}$ mice in response to light pulses in constant darkness. After 4 weeks in continuous darkness, one cohort of $\mathrm{CBP}^{\mathrm{KIX} / \mathrm{KIX}}$ mice and WT controls was given a 15-min, $250 \mathrm{~lx}$ (80 lx at cage floor) phase delaying light pulse at CT14 for maximal phase delay [75]. Circadian period length was recalculated and the phase shift in hours was calculated for each animal. Mice were allowed to again free-run in constant darkness for 8 days before receiving another light pulse, this time phase-advancing, at CT22 (Fig. 6a). There were no differences in response to the delaying (CT14) or advancing (CT22) phase shifts between $\mathrm{CBP}^{\mathrm{KIX} / \mathrm{KIX}}$ mice and WT controls (Fig. 6b-d). 

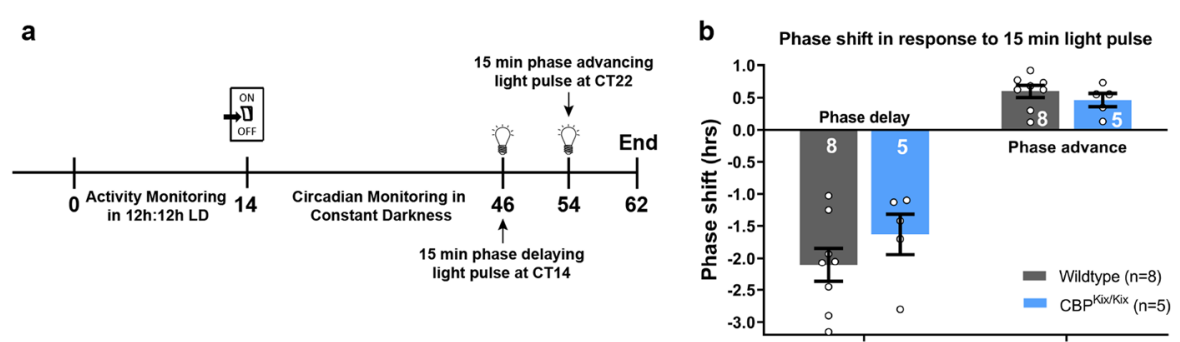

C

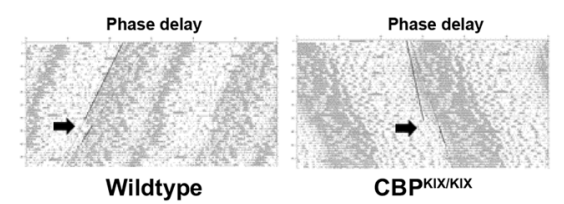

d

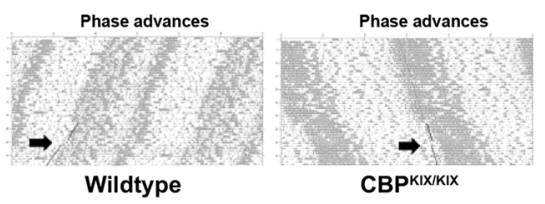

Fig. $6 \mathrm{CB} \mathrm{PIIKKIX}^{\mathrm{K}}$ mice exhibit normal responses to phase advances and phase delays. a Schematic representation of experimental timeline in days for circadian monitoring and light pulse experiments. $\mathbf{b} C \mathrm{CBP}^{\mathrm{KI} / \mathrm{KIX}}$ and WT mice display comparable phase shifts when given either a phase delaying (CT14) or phase advancing (CT22) light pulse (Student's $t$ test, phase delaying: $\left(t_{(11)}=1.15, p=0.27\right)$; phase advancing: $\left.\left(t_{(11)}=0.93, p=0.37\right)\right)$. c Representative actograms from $C T 14$ phase delaying light pulse for wildtype (left) and CBP ${ }^{K I X / K I X}$ (right) mice. $\mathbf{d}$ Representative actograms from $C T 22$ phase advancing light pulse for wildtype (left) and CBP ${ }^{\mathrm{KI} / \mathrm{KIX}}$ (right) mice. ${ }^{*} p<0.05,{ }^{* *} p<0.01,{ }^{* * *} p<0.001$

These data suggest that CBP-mediated transcription through the KIX domain is not necessary for circadian clock resetting, but rather is a modulator that plays a role in ensuring accurate timing of circadian transcriptional oscillations.

\section{Discussion}

CBP is a complex co-activator of transcription interacting with numerous transcription factors as well as functioning as a histone acetyltransferase important in longterm memory. To separate the multiple functions of CBP and provide clearer insight into the downstream targets of CREB-CBP transcriptional co-activation in memory, we used $\mathrm{CBP}^{\mathrm{KIX} / \mathrm{KIX}}$ mice with three point mutations in the KIX domain to analyze spatial memory following hippocampus-dependent learning and to identify downstream target genes. We found that $\mathrm{CBP}^{\mathrm{KIX} / \mathrm{KIX}}$ mice learned a complex spatial task, the MWM, with acquisition rates similar to WT mice. However, long-term spatial memory tested $24 \mathrm{~h}$ following the last day of MWM training was impaired in $\mathrm{CBP}^{\mathrm{KIX} / \mathrm{KIX}}$ mice. These results are consistent with previously described $C b p$ mutant models with deficiencies in hippocampusdependent memory including contextual fear conditioning and object recognition memory [19-21]. However, previous research using an adult specific forebrain $\mathrm{Cbp}$ knockout model found no deficits in long-term memory for MWM or contextual fear conditioning in the mutant mice [21]. Potentially, compensation by other transcription factors or co-activators occurs to make-up for the complete lack of forebrain CBP in these mutants. Thus, our results suggest a crucial role for the interaction of the KIX domain of CBP with transcription factors during the consolidation of long-term spatial memory.

Despite the lack of long-term spatial memory evident in $\mathrm{CBP}^{\mathrm{KIX} / \mathrm{KIX}}$ mice, these mice demonstrated memory recall in the 1-h probe test comparable to WT mice, consistent with most previous research investigating short term-memory for contextual fear conditioning and object recognition in $C b p$ mutants $[19,20]$. It should be noted that deficits in associative short-term memory were found for contextual fear conditioning and novel object recognition in the forebrain $C b p$ knockout model that results in virtually complete depletion of CBP protein in excitatory neurons of the hippocampus and the cortex [76]. In contrast, in the $\mathrm{CBP}^{\mathrm{KIX} / \mathrm{KIX}}$ mutant mice used in our studies, overall CBP protein levels and protein stability are not affected $[19,41]$. In $\mathrm{CBP}^{\mathrm{KIX} / \mathrm{KIX}}$ mice, CBP retains the potential to interact with non-KIX binding transcription factors to induce gene expression and $\mathrm{CBP}$ can also still function as an acetyltransferase. Although $\mathrm{CBP}^{\mathrm{KIX} / \mathrm{KIX}}$ mice express the mutant form of CBP from developmental stages onward, we found only modest changes in baseline gene expression between $\mathrm{CBP}^{\mathrm{KIX} / \mathrm{KIX}}$ mice and WT littermates under homecage conditions.

To provide insight into the downstream transcriptional targets common to multiple hippocampus-dependent learning paradigms initiated through co-activation of CBP via the KIX domain, we performed deep RNA sequencing from the dorsal hippocampus of $\mathrm{CBP}^{\mathrm{KIX} / \mathrm{KIX}}$ mice and their WT littermates after training for either MWM or contextual fear conditioning. Consistent with the specificity of the mutations in the $\mathrm{CBP}^{\mathrm{KIX} / \mathrm{KIX}}$ mice, we found that CREB was the top-predicted upstream 
regulator of the differentially regulated genes in learning for $\mathrm{CBP}^{\mathrm{KIX} / \mathrm{KIX}}$ vs WT mice. To further support the hypothesis that compromised CREB-CBP interactions underlie the long-term deficits in hippocampal memory in $\mathrm{CBP}^{\mathrm{KIX} / \mathrm{KIX}}$ mice, we found that PCREB was decreased in $\mathrm{CBP}^{\mathrm{KIX} / \mathrm{KIX}}$ mice following 3 days of MWM training compared to WT mice. As Ser-133 phosphorylation is necessary for the binding of CREB to CBP and induces folding of the CREB kinase inducible domain (KID), the decreased binding of CREB to CBP may increase CREB vulnerability to phosphatase activity in the $\mathrm{CBP}^{\mathrm{KIX} / \mathrm{KIX}}$ mice as total CREB protein levels were not affected. Prior to binding CBP, the KID of CREB remains chiefly unstructured and is considered disordered with CBP binding increasing the helical structure of the KID region [77].

Our RNA-Seq results from the WT group comparison (learning versus homecage) support the present literature that learning induces CREB and CREM target genes that both interact with CBP [12, 78, 79]. Among the CREB downstream genes, we found several activitydependent genes (Arc, Egr1, Fos, Nr4a1, JunB) that previously have been shown to be upregulated following hippocampus-dependent learning [31, 80, 81]. It is noteworthy that some of these activity-dependent genes were downregulated in $\mathrm{CBP}^{\mathrm{KIX} / \mathrm{KIX}}$ mice, including Nr4a1. The role of the Nr4A sub-family has been well characterized in memory. Reducing Nr4A function in the hippocampus impairs long-term memory [82-84], while the activation of Nr4A family transcription factors enhances memory in young [85] and aged mice [86, 87]. Pharmacological activation of CBP in a mouse model of Alzheimer's disease rescues $N r 4 A$ gene expression and long-term memory [31].

Notably, we found that genes involved in circadian rhythms were significantly dysregulated in the dorsal hippocampus of $\mathrm{CBP}^{\mathrm{KIX} / \mathrm{KIX}}$ mice following learning including Per1, Per2, Per3, Dbp, Nr1d1, Nr1d2, and Ciart/ Chrono/ Gm129. IPA analysis revealed the major upstream regulators of the downregulated circadian genes in $\mathrm{CBP}^{\mathrm{KIX} / \mathrm{KIX}}$ mice following learning were CREB, CLOCK, and BMAL1, emphasizing the interaction between CBP and the circadian oscillator. Although the suprachiasmatic nucleus (SCN) houses the master circadian clock in mammals, circadian rhythms and circadian genes in the hippocampus have been associated with memory. Performances in hippocampus-dependent tasks including the radial arm maze, spontaneous alteration, novel object location, contextual fear conditioning, passive avoidance, and MWM are time of day dependent (reviewed in [88]). The formation and persistence of long-term hippocampal memory has been associated with circadian rhythms in cAMP and MAPK signaling through CREB-mediated transcription [89]. Hippocampal PER1 has been postulated to function as a gatekeeper conveying time of day information to signaling pathways involved in memory formation through the regulation of CREB phosphorylation [57, 59]. While these previous studies indicate that the circadian clock regulates CREB-mediated transcription in the hippocampus to affect memory formation, our data suggests reciprocal interactions with CBP transcriptional co-activation mediating Per gene expression after learning. Our research suggests that in the hippocampus, Per1 and Per2 transcription is dependent upon CBP transcriptional coactivation similar to the CBP-CREB-dependent regulation of Per genes seen in the SCN $[90,91]$.

Previously, in vitro research has indicated that CBP modulates circadian rhythms and interacts with BMAL1 in phase resetting of the circadian clock [40]. Moreover, siRNA knockdown of CBP significantly diminishes circadian oscillations in cultured cells [40]. However, no previous studies in mammalian models have examined the effects of CBP mutations on circadian rhythms in vivo. We found that under diurnal conditions, $\mathrm{CBP}^{\mathrm{KIX} / \mathrm{KIX}}$ mice exhibited delayed activity onset with peak activity occurring significantly later in the night compared to sex-matched controls. In constant darkness, both male and female $\mathrm{CBP}^{\mathrm{KIX} / \mathrm{KIX}}$ mice have significantly longer free-running periods. During preparation of this manuscript, high-resolution structural research identified direct interactions between the $\mathrm{C}$-terminal transactivation domain of BMAL1 with the KIX domain of CBP [92]. Previous in vitro research found that the KIX domain of CBP and CRY 1 competed for binding at the TAD domain of BMAL1 highlighting the fine-tuned regulation of circadian period length [93]. Thus, it appears possible that CBP affects circadian clock function through independent interactions with circadian transcription factors, particularly BMAL1, in addition to transcriptional coactivation with phospho-CREB (Ser133). The role of CBP in the circadian clock appears highly conserved. In Drosophila, CBP has been shown important in circadian gene transcription regulating the CLOCK/CYCLE activation of transcription [94-97]. Similar to what we observed in mice, when CBP levels are decreased in circadian pacemaker neurons, the period is lengthened in Drosophila [96]. Moreover, the regulation of CBP levels appears to be a critical factor in the maintenance of normal circadian function as overexpression of CBP induces behavioral arrhythmicity in Drosophila [94, 97].

Despite the temporally delayed activity pattern and longer free-running rhythms seen in $\mathrm{CBP}^{\mathrm{KIX} / \mathrm{KIX}}$ mice, we found no difference between phase resetting in mutant mice and WT by light pulses delivered in the early or late night. The dissociation between the impact of KIX domain mutations on different functions of the circadian clock is consistent with the multiple domain nature of the CBP protein. For phase resetting of the 
circadian clock, the interactions between CBP and BMAL1 at the Per1 promoter are thought to be primarily reliant upon calcium-dependent PKC signaling following resetting stimuli and not CREB [40]. CBP has been postulated to interact with BMAL1 through the PXDLS motif (Pro-X-Asp-Leu-Ser), a conserved motif in multiple circadian proteins and present in CBP [64]. Our in vivo studies differentiating the impact of KIX mutations on period length and phase resetting support the hypothesis that different signaling pathways trigger CBP involvement in these two functions. Since phase shifts in response to light have been shown to be, at least in part, CREB-dependent, CREB also may act through binding to other co-activators such as CREB-regulated transcription coactivator (CRTC1) in phase resetting via Per1 in the SCN $[98,99]$.

While our study shows a dual role for the CBP KIX domain in spatial long-term memory consolidation and the maintenance of normal circadian periods, we cannot absolutely determine the relationship between the two functions of CBP. As the $\mathrm{CBP}^{\mathrm{KIX} / \mathrm{KIX}}$ mutation is a whole body mutation, the Kix domain of CBP is mutated in the SCN, the master circadian clock controlling transcriptional and behavioral rhythms, which presumably underlies the lengthening of the free-running period and the activity delays. Of particular relevance, previous research has found that arrhythmia in the SCN circadian clock results in hippocampal memory impairments $[100,101]$. Thus, it is possible that alterations in the circadian function of the SCN result in changes in other brain clocks such as in the hippocampus to cause memory impairments. However, as shown in our studies, we found that the $\mathrm{CBP}^{\mathrm{KIX} / \mathrm{KIX}}$ mutation did not cause circadian arrhythmia, but instead $\mathrm{CBP}^{\mathrm{KIX} / \mathrm{KIX}}$ mice exhibited a lengthening of the freerunning period under constant conditions and a delay in activity during the dark phase during both LD and DD conditions. Furthermore, no activity differences were observed between $\mathrm{CBP}^{\mathrm{KIX} / \mathrm{KIX}}$ mice and wild-type mice during the light phase when the training for learning occurred in our experiments (ZT3-ZT6). These results make it unlikely that changes in the SCN circadian oscillator underlie the impairments in hippocampus memory consolidation that we observed. Additionally, the differential expression of several core circadian genes between wildtype and $\mathrm{CBP}^{\mathrm{KIX} / \mathrm{KIX}}$ mice were observed specifically after hippocampus-dependent learning, but not under homecage conditions (Fig. 4, Additional file 1: Fig. S5, Table 1, Additional file 2: Table S1). While beyond the scope of the present investigation, future studies involving site-specific mutation of $\mathrm{CBP}^{\mathrm{KIX} / \mathrm{KIX}}$ restricted specifically to the adult hippocampus or SCN will be an important avenue of exploration to more fully elucidate the relationship between the impairments in learning and the circadian clock.
While performing these studies at the same circadian time (ZT3-ZT6) allows for direct comparison between experiments through minimization of changes in gene expression due to circadian regulation, it is possible that the downregulation of circadian genes observed in $\mathrm{CBP}^{\mathrm{KIX} / \mathrm{KIX}}$ mice represents a change in gene expression due to phase shifts of the circadian oscillator. However, we find this possibility to be unlikely as we did not observe any significant phase shifts in the locomotor activity profiles of these animals during the light phase nor did we find widespread changes in gene expression under homecage conditions that would be likely if circadian gene cycling was affected. Nonetheless, understanding the effect of $\mathrm{CBP}^{\mathrm{KIX} / \mathrm{KIX}}$ on memory and circadian transcription across multiple circadian times is an important future direction necessary to fully understand the multiple roles of CBP.

\section{Conclusions}

Our research on the CBP KIX domain provides significant insight into two processes that significantly impact healthy aging, memory, and circadian rhythms. Although overall CBP protein levels appear unchanged with aging in one rat model [102], potentially, changes in CREBCBP interactions through the KIX domain could be linked to age-related memory impairments. Mutations in CBP have been associated with neurodegenerative diseases including Huntington's disease [32,33] and Alzheimer's disease [34-36]. Post-mortem brain analysis in humans and animal models have found decreased CREB expression associated with many neurological and neurodegenerative disorders including Alzheimer's disease, Parkinson's disease, bipolar disorder, and schizophrenia [31, 103-105]. In a mouse model of Alzheimer's disease, viral delivery of CBP restores PCREB levels and mitigates cognitive impairments [106]. Our research highlights the role the CBP KIX domain plays in the regulation of circadian gene expression and circadian activity as well as its role in long-term memory. Maintaining robust circadian rhythms is also essential for healthy aging. Agerelated changes in circadian function include the dampening of molecular circadian rhythms, changes in freerunning period, and impairments in the synchronization and coordination of circadian oscillators across tissues and organs (reviewed in [107]). The longer free running period in $\mathrm{CBP}^{\mathrm{KIX} / \mathrm{KIX}}$ mice with delayed activity onset is reminiscent of the circadian phenotypes seen in aging mice. Aged mice have significantly longer free-running periods and exhibit a delay in activity onset after dark compared to younger adult mice [108]. Recent evidence suggests that circadian rhythm disruptions may contribute to increased risk or aggravation of disease pathology for neurodegenerative diseases including Alzheimer's disease and Parkinson's disease [109-114]. Additionally, 
recent research suggests that hippocampal Per1 specifically may be critical to age-related cognitive impairments [58]. The CBP KIX domain appears to represent a potential target for understanding the effects of circadian and memory impairments that occur with aging. With life expectancy predicted to continue rising [115], identifying the regulatory mechanisms and molecular processes underlying the formation of memory is a necessary step for the development of future therapies and treatments for memory impairments.

\section{Methods}

\section{Animals}

The $\mathrm{CBP}^{\mathrm{KIX} / \mathrm{KIX}}$ mice for experiments were generated from heterozygous mating (from C57BL/6 J genetic background), with wildtype (WT) littermates used as controls. Mice were approximately 3 months old at the start of experiments. Male and female mice were used in experimental and control groups. Mice were housed in groups of 2-3 under 12 -h light/12 h-dark cycle in a temperature- and humidity-controlled room $\left(22^{\circ} \mathrm{C}\right.$ and $55 \pm 5 \%$, respectively) with ad libitum access to food and water. All behavioral training and testing (with the exception of circadian monitoring) was performed during the light portion of the cycle (lights on at 7:00 A.M.) at the same time of day. Experimental protocols and animal care at the University of Strasbourg were in compliance with the institutional guidelines laws and policies (the European Parliament 2010/63/UE of September 22, 2010). All experiments at the University of Pennsylvania were approved by the University of Pennsylvania Institutional Care and Use Committee (IACUC protocol 804407) and conducted in accordance to National Institute of Health guidelines.

\section{Morris water maze}

Evaluation of spatial memory was performed using the Morris Water Maze task (MWM) as described in Chatterjee et al. [30]. For the spatial memory tests, two independent groups of mice $\mathrm{CBP}^{\mathrm{KIX} / \mathrm{KIX}}$ and their $\mathrm{WT}$ littermates were trained for 5 days. Each training day consisted of four trials of maximum duration of $60 \mathrm{~s}$ in each trial to locate a hidden platform under the surface of water using the visual cues present in the room. After the last training session, the platform was removed, and each group of animals was tested (probe test) to measure short-term memory $1 \mathrm{~h}$ later or $24 \mathrm{~h}$ later to measure long-term memory. During the probe test, the mice were placed in the opposite quadrant with respect to the target quadrant and allowed to swim for $60 \mathrm{~s}$. Spatial memory during the probe test was quantified by measuring the amount of time spent by the mice searching in the target quadrant versus the average time spent in the three other quadrants. For the biochemical studies, mice were trained for three consecutive days. Three days of training using this protocol has previously been shown sufficient to induce CBP-dependent gene expression changes in the dorsal hippocampus [116]. One hour after the last trial on the 3rd day, the dorsal hippocampus was immediately dissected, frozen in liquid nitrogen, and stored at $-80^{\circ} \mathrm{C}$. All the animals were euthanized between ZT3 and ZT6 for tissue collection for gene expression studies. This time point was chosen based on our previous publications $[31,116]$ in which we showed that 3 days of training in the MWM was sufficient to increase CBP expression in the dorsal hippocampus, increased CBP binding to the promoter of target genes, increased histone acetylation, and increased upregulation of target gene expression.

\section{Contextual fear conditioning}

Contextual fear conditioning was performed as previously described [117] with mice handled 1 min per day for three consecutive days prior to fear conditioning training. On the training day, the mice received a single $2 \mathrm{~s}, 1.5 \mathrm{~mA}$ foot-shock culminating $2.5 \mathrm{~min}$ after placement into the chamber. Mice were removed from the chamber $30 \mathrm{~s}$ after receiving the foot shock and returned to their homecages. One hour after the end of training, animals were euthanized and dorsal hippocampi were quickly dissected for RNA extraction. A separate group of mice serving as homecage controls were handled but did not receive the electric shock. All the animals were euthanized between ZT3 to ZT6 for gene expression studies.

\section{Microarray}

For the microarray homecage experiments, WT or $\mathrm{CBP}^{\mathrm{KIX} / \mathrm{KIX}}$ mice were handled for three consecutive days prior to tissue collection. Animals were euthanized between ZT3 and ZT6, hippocampi were quickly dissected and total RNA was extracted. Microarray analysis was performed with Affymetrix MOE 430v2 arrays probed with labeled RNA from the two hippocampi of each animal as a single biological replicate. RNA was obtained using a TRIzol-chloroform extraction followed by RNAeasy (Qiagen) isolation. RNA quality was assessed with the Agilent Bioanalyzer. RNA amplification and labeling were performed with the NuGen ovation system. After hybridization and array reading at the Penn Microarray Facility, intensity scores were calculated by the Robust Multiarray Average (RMA) method [118], and quality control was performed using array Quality Metrics [119] to ensure that differences in signal intensity did not bias analysis. Following the RMA, patterns from Gene Expression (PaGE v5.1) analysis were implemented in Perl to assess confidence in changes in probe set expression level between $\mathrm{CBP}^{\mathrm{KIX} / \mathrm{KIX}}$ and wildtype littermates. This algorithm uses permutations of the input 
data to empirically determine the false discovery rate (FDR) for a given $T$-statistic level, allowing assignment of FDR values to individual probe sets based on a modified $T$-statistic. FDR values were computed with 200 permutations, and multiple instances of FDR calculation were run to assess confidence levels (1-FDR) from 80 to 95\%.

\section{RNA extraction for RNA-seq library preparation and sequencing}

Dorsal hippocampus was quickly dissected, placed into RNA later (Qiagen Valencia, CA), or frozen in liquid nitrogen. Tissues were homogenized in QIAzol Lysis Reagent (Invitrogen) and mixed in chloroform. RNA in aqueous-phase was separated in phase-lock tubes following centrifugation at $14,000 \mathrm{~g}$ for $15 \mathrm{~min}$. RNA was extracted using RNAeasy kit (Qiagen) according to the manufacturer's instruction. Samples were DNase treated using the RNase-Free DNase kit (Qiagen) off-column. Samples were ethanol precipitated and resuspended in RNAse-free water. Samples with an OD 260/280 and OD 260/230 ratio close to 2.0 and RNA integrity number (RIN) above 8 were selected for library preparation.

\section{RNA library preparation and sequencing from homecage and fear conditioned mice}

RNA library from homecage and fear conditioned mice were prepared at the PGFI sequencing core at the University of Pennsylvania using the TruSeq sample preparation kit (Illumina San Diego, CA) according to the manufacturer's instructions with polyA selection. Libraries were size selected and quantified by qPCR (KAPA Biosystems Boston, MA) and sequenced. Barcoded libraries were sequenced in Illumina HiSeq 2000 in paired-end 100-bp reads. Three libraries were sequenced per lane on an Illumina HiSeq 2000 at the sequencing core at the University of Pennsylvania.

\section{RNA library preparation and sequencing from homecage and MWM mice}

RNA libraries from homecage and MWM mice were prepared at the Iowa Institute of Human Genetics (IIHG), Genomics Division, using the Illumina TruSeq Stranded Total RNA with Ribo-Zero gold sample preparation kit (Illumina, Inc., San Diego, CA). Library concentrations were measured with KAPA Illumina Library Quantification Kit (KAPA Biosystems, Wilmington, MA). Pooled libraries were sequenced on Illumina HiSeq 4000 sequencers with 150-bp Paired-End chemistry (Illumina) at the IIHG core.

The RNA seq data have been deposited in NCBI's Gene Expression Omnibus and are accessible through GEO Series accession number GSE151681 (https://www. ncbi.nlm.nih.gov/geo/query/acc.cgi?acc=GSE151681).
The code for analyses and figures related to RNA-seq data can be accessed through GitHub (github.com/ ethanbahl/chatterjee2020_cbpkix).

\section{$C D N A$ synthesis and quantitative real-time reverse transcription (RT)-PCR}

cDNA preparation was done using SuperScript ${ }^{\mathrm{Tm}}$ IV First-Strand Synthesis System (Ambion) from $1 \mu \mathrm{g}$ total RNA. Real-time RT-PCR reactions were performed in 384-well optical reaction plates with optical adhesive covers (Life Technologies). Each reaction was composed of $2.25 \mu \mathrm{l}$ cDNA ( $2 \mathrm{ng} / \mathrm{ul}), 2.5 \mu \mathrm{l}$ Fast SYBR ${ }^{\mathrm{m}}$ Green Master Mix (ThermoFisher Scientific), and $0.25 \mu \mathrm{l}$ of primer mix (IDT). Reactions were performed in at least triplicate on the Quant studio 7 Flex Real-Time PCR system (Applied Biosystems, Life Technologies). Hprt and Pgk1 were used as housekeeping controls for normalization.

\section{RNA-seq analysis}

Sequencing data was processed with the bcbio-nextgen pipeline (https://github.com/bcbio/bcbio-nextgen). The pipeline uses STAR [120] to align reads to the genome and quantifies expression at the gene level with featureCounts [121]. All further analyses were performed using $R$ [122]. For gene level count data, the $R$ package EDASeq was used to adjust for GC content effects (full quantile normalization) and account for sequencing depth (upper quartile normalization) [123] (Additional file 1: Fig. S8 and S9). Latent sources of variation in expression levels were assessed and accounted for using RUVSeq (RUVr) [124] (Additional file 1: Fig. S10 and S11). Appropriate choice of the RUVSeq parameter $k$ was determined through inspection of $P$ value distributions, mean-difference plots, RLE plots, and PCA plots. Specifically, values of $k$ were chosen where $P$ value distributions showed an expected peak below 0.05 [125] and experimental groups were separable with three principal components. Differential expression analysis was conducted using edgeR [126, 127].

We performed three differential expression analyses to identify genes responsive to learning in wildtype mice, genes responsive to the $\mathrm{CBP}^{\mathrm{KIX} / \mathrm{KIX}}$ genotype following learning, and genes responsive to the $\mathrm{CBP}^{\mathrm{KIX} / \mathrm{KIX}}$ genotype at baseline. Based on criteria listed above, we used $k$ values of 3, 4, and 0 for the analyses. Data generated from two experimental batches using different hippocampus-dependent learning paradigms were included in the differential expression models. Due to this experimental design, effects specific to a particular experiment (both sequencing batch effects and paradigmspecific effects) were accounted for in the models by including experimental batch as a blocking variable, thus revealing genes reproducibly responsive to learning or 
the $\mathrm{CBP}^{\mathrm{KIX} / \mathrm{KIX}}$ genotype across multiple paradigms of hippocampus-dependent learning.

To externally validate our analysis, we used previously published research on gene regulation in the hippocampus following chemically induced neuronal activation [55]. We created a positive control set (Additional file 2: Table S4 with list of positive controls) using genes in the top decile of adjusted $P$ values (adjusted $P<0.05$ ). We performed Fisher's exact test on a two-dimensional contingency table, with rows indicating whether a gene was responsive to learning in our study, and columns indicating whether the gene was in the positive control set. Using this approach, we also tested the set of genes responsive to the $\mathrm{CBP}^{\mathrm{KIX} / \mathrm{KIX}}$ genotype, after learning, for enrichment of genes responsive to learning in WT animals. As an alternative approach to assessing commonalities between these expression signatures, we also performed a rank-rank hypergeometric overlap (RRHO) analysis [128]. We ordered genes in each list by $P$ value and used a step size of 100 genes to identify FDR thresholds for each list, which conferred maximal overlap in gene signatures. We then used the $\mathrm{R}$ package cluster Profiler [129] to compare gene ontology enrichment identified for traditional thresholds compared to thresholds supporting maximal RRHO enrichment.

\section{Upstream regulator and pathway analysis}

Upstream regulator analysis was performed using the QIAGEN's Ingenuity ${ }^{\odot}$ Pathway Analysis (Qiagen Redwood City, CA, USA, www.qiagen.com/ingenuity) as described in Lorsch et al. [130]. Global enrichment network analysis from KEGG pathway database was performed using the free online NetworkAnalyst software 3.0 (https://www.networkanalyst.ca).

\section{Activity monitoring}

Activity monitoring was performed as previously described in a separate group of mice from the RNA-seq/ microarray/ behavioral experiments [65, 131]. Briefly, mice were individually housed inside light- and noiseattenuating chambers $\left(22^{\prime \prime} \times 16^{\prime \prime} \times 19^{\prime \prime}\right.$, Med Associates, St. Albans, VT) equipped with a 250 -lx light source (80 $\mathrm{lx}$ at cage floor) and fan for ventilation. Each cage was placed within a system of infrared beams spaced $0.5 \mathrm{in}$. apart that provided two horizontal infrared grids at $0.75^{\prime \prime}$ and $2.75^{\prime \prime}$ above the cage floor. Mice were allowed to acclimate to the activity monitoring chambers for 1 week before the start of activity monitoring. Infrared beam break counts were acquired at $10 \mathrm{~s}$ intervals for 7 days on a 12-h:12-h LD schedule to measure both horizontal and vertical (rearing) activity across the entire diurnal cycle. Activity counts were binned into 1-h intervals and averaged over the 7 days. After the final day of activity monitoring in LD cycles, lights were switched off and animals were allowed to free-run in 24 $\mathrm{h}$ constant darkness (DD) for 4 weeks with activity counts compiled every minute. Circadian period (tau) was calculated from day 2 until the end of DD using ClockLab software (Actimetrics).

\section{Light pulses}

Following 4 weeks of constant darkness, one cohort of mice ( $n=8 \mathrm{WT}$ and $n=5 \mathrm{CBP}^{\mathrm{KIX} / \mathrm{KIX}}$ ) received a $15-\mathrm{min}$ phase delaying 250-lx (80 lx at cage floor) light pulse at CT 14. Mice were allowed to recover for 8 days in 24-h constant darkness, and the phase shift was measured. After the 8 days in continuous darkness, a second 15min phase advancing light pulse was given at CT 22 . The phase angles of activity delay and advancement were calculated using ClockLab software (Actimetrics).

\section{Statistical analyses}

All statistics were performed using Graphpad Prism (V8.1), except for circadian analysis which was performed using SPSS for Windows (v 24.0) and the bioinformatics analysis. For MWM, performance recorded during acquisition (latency to the platform) was evaluated using a one- or two-way ANOVA with repeated measures when appropriate. Escape latencies during acquisition were analyzed using two-way ANOVA, followed by Sidak's multiple comparisons test. Probe trial performance was also analyzed using two-way ANOVA, followed by Sidak's multiple comparisons test comparing the time spent in the target quadrant $(\mathrm{T})$ and the time spent in the other three quadrants (Q1-3). Homecage activity was analyzed using a Mixed ANOVA with genotypes (WT and $\mathrm{CBP}^{\mathrm{KIX} / \mathrm{KIX}}$ ) as the betweensubjects factor and time as the within-subject factor. Post hoc multiple comparisons were performed. Multivariate ANOVAs (MANOVA) were used to analyze the activity counts in the light and dark phases, with alpha corrected for multiple ANOVAs and set at $\alpha=0.05 / 2$. For total activity over the 24-h day and light pulse analysis, Student's $t$ test was applied. Results were expressed as means \pm SEM. Values of $p<0.05$ were considered as statistically significant.

\section{Supplementary information}

Supplementary information accompanies this paper at https://doi.org/10. 1186/s12915-020-00886-1.

\footnotetext{
Additional file 1: Fig. S1. CBP ${ }^{\mathrm{KIX} / K I X}$ mice show normal learning, reduced swim speed and impaired long-term memory. a CBP ${ }^{\mathrm{KI} / \mathrm{KIX}}$ mice show similar performance during trial 1 across training days 1-4 but shows significantly higher escape latency on day 5. 2-Way ANOVA: significant main effect of training days: $F_{(3.318,99.55)}=4.538, p=0.0038$, significant main effect of genotype: $F^{(1,30)}=9.507, p=0.0044$. Sidak's multiple comparisons test, comparing $\mathrm{CBP}^{\mathrm{KIX} / \mathrm{KIX}}$ vs WT on Day 5: adjusted $p=$ 0.0120. b CBP ${ }^{\mathrm{KIX} / \mathrm{KIX}}$ mice showed lower swim speed during the training days (acquisition). Significant main effect of genotype: $F(1,30)=15.33$,
} 
$p=0.0005$. Sidak's multiple comparisons test revealed significant decrease in swim speed (CBP $P^{\mathrm{KI} / \mathrm{KIX}}$ vs WT mice) on day $4(p=0.0067)$ and day 5 $(p=0.0417)$. c Male and female CBP ${ }^{\mathrm{KI} / \mathrm{KIX}}$ mice showed similar performances during the $1 \mathrm{~h}$ probe test (short-term memory). d Male and female CBP ${ }^{\mathrm{KI} / \mathrm{KI} X}$ mice showed similar performances in the $24 \mathrm{~h}$ probes test (long-term memory). Mixed-effects analysis: Significant main effect of Genotype $F_{(1,12)}=11.36, p=0.0056$. No significant main effect of sex $F_{(1,}$ 12) $=0.3330, p=0.5746$. Fig. S2. Learning-induced CREB phosphorylation at $\mathrm{S} 133$ is decreased in CBP ${ }^{\mathrm{KI} / \mathrm{K} / \mathrm{LI}}$ mice. (a) Scheme of the experiment. (b) CREB phosphorylation at S133 is significantly increased after MWM training ([Unpaired t-test: $\mathrm{t}_{(11)}=2.407, p=0.0348$, WT HC Vs WT MWM], while no such enhancement were observed in $\mathrm{CBP}^{\mathrm{KI} / \mathrm{KIX}}$ mice [Unpaired t-test: $\left.\mathrm{t}_{(7)}=0.7450, p=0.4805\right]$. (c) Western blot showing CREB and $p$ CREB expression. Fig. S3. RRHO analysis. a Rank-rank hypergeometric overlap (RRHO) analysis comparing differential expression results between the effect of the KIX genotype after learning (X-axis) to the effect of learning (Y-axis). Although a threshold of FDR $<=0.05$ corresponds to the top 158 and 135 genes for the $X$ and $Y$ axis, respectively, we observe maximum hypergeometric enrichment between the two lists when considering the top 500 genes from each list, corresponding to FDR thresholds of 0.133 and 0.146 for the $X$ and $Y$ axis, respectively (circle). b Comparison of gene ontology enrichment for overlapping genes using traditional FDR thresholds (FDR $<=0.05$ ), and relaxed thresholds identified by RRHO. $\mathrm{RRHO}$ thresholds also revealed significant enrichment of several terms not discovered with FDR $<=0.05$, including terms related to postsynaptic localization and additional transcription factor and hormone receptor binding terms. Compared to the stricter threshold of FDR $<=0.05$, RRHO thresholds reduced enrichment of several signficant gene ontology terms related to circadian rhythm, histone deacetylation, and transcription factor binding, suggesting these biological signals are primarily derived from statistically significant genes at $F D R<=0.05$. Fig. S4. CBP gene expression is unaltered in $C B P^{K I / K I X}$ mice. The four probe sets for CBP, official gene symbol Crebbp, are shown. Only the probe set that hybridizes to the KIX domain (1459804_at) shows evidence of reduced signal intensity in $\mathrm{CBP}^{\mathrm{KI} / \mathrm{KIX}}$ mice. The approximately $40 \%$ reduction in signal only for this probe set is likely due to the three base pair mutations introduced by the KIX domain mutation. Fig. S5. CBP $P^{\mathrm{KI} / K \mathrm{KI}}$ mice shows normal expression of core circadian genes in homecage. Circadian gene expression were accessed at baseline from wildtype and CBP ${ }^{\mathrm{KI} / \mathrm{K} / \mathrm{X}}$ mice. Per1, Per2, Clock, Bmal, Nr1d1 and Nr1d2 showed similar levels of expression, while Dbp showed significant decrease in $\mathrm{CBP}^{\mathrm{KI} / \mathrm{KIX}}$ mice (unpaired t-test $p=$ 0.0214). All the animals were euthanized between ZT3-ZT6. Fig. S6. Homecage RNA-seq analysis. Volcano plot showing only 2 genes are differentially expressed in CBP $P^{K I / K I X}$ mice compared to WT mice in dorsal hippocampus at homecage. Fig. S7. Delayed peak diurnal activity in male and female CBP $P^{\mathrm{KI} / \mathrm{KI}}$ mice. $\mathbf{a}, \mathbf{b} C \mathrm{CB}^{\mathrm{KI} / \mathrm{K} / \mathrm{X}}$ males have delayed activity onset and peak activity in $12 \mathrm{~h}: 12 \mathrm{~h} \mathrm{LD}$ compared to wildtype littermates (a) (time ${ }^{*}$ genotype, $\mathrm{F}_{(23,368)}=6.13, p=0.002$ ), without exhibiting differences in total ambulation (b) $\left(\mathrm{t}_{(16)}=1.16, p=0.307\right)$. $\mathbf{c}, \mathbf{d} C \mathrm{CBP}^{\mathrm{KIX} / \mathrm{KIX}}$ females also have delayed diurnal activity patterns compared to wildtype (c) $\left(F_{(223)}=7.95, p<0.001\right)$, while total movement is unaltered between $\mathrm{CBP}^{\mathrm{KI} /} / \mathrm{klX}$ females and wildtype controls $(\mathbf{d})(\mathrm{t}(10)=1.11, p=0.316) .{ }^{*} p<$ $0.05,{ }^{* *} p<0.01 .{ }^{* * *} p<0.001$. Fig. S8. Normalization of differences in GC content distribution and sequencing depth using EDASeq for comparisons of RNAseq studies after learning in wildtype mice and CBP ${ }^{K I X / k I X}$ mice. Distributional differences in GC content and variability in sequencing depth are sources of technical variability in RNA-sequencing data. ac, GC content distributions before normalization (a), after full quantile GC content normalization $(\mathbf{b})$, and upper quartile sequencing depth normalization (c). d-f, Relative log expression (RLE) plots before normalization (d), after full quantile GC content normalization (e), and upper quartile sequencing depth normalization (f). g-i, Principal component analysis (PCA) plots before normalization ( $\mathbf{g}$ ), after full quantile GC content normalization (h), and upper quartile sequencing depth normalization (i). Fig. S9. Normalization of differences in GC content distribution and sequencing depth using EDASeq for comparisons of RNAseq studies between homecage wildtype mice and trained wildtype mice. a-c, GC content distributions before normalization (a), after full quantile GC content normalization (b), and upper quartile sequencing depth normalization (c). d-ff, Relative log expression (RLE) plots before normalization (d), after full quantile GC content normalization (e), and upper quartile sequencing depth normalization (f). g-i, Principal component analysis (PCA) plots before normalization ( $(\mathbf{g})$, after full quantile GC content normalization (h), and upper quartile sequencing depth normalization (i). Fig. S10. RUV normalization for analysis of RNAseq after learning in wildtype mice and $\mathrm{CBP} \mathrm{P}^{\mathrm{KI} / \mathrm{KI} X}$ mice. RUV normalization removes unwanted variation that dwarfs biological signal in RNA-sequencing data. Left. Without applying RUV normalization, uncorrected $P$-values from the differential expression analysis are uniformly distributed and few genes are found to be statistically significant at false discovery rate $(F D R)<=$ 0.05 after multiple testing correction $(\mathbf{a}, \mathbf{c})$. RLE and PCA plots reveal traditional normalization approaches fail to allow separation of biologically meaningful groups using three principal components* $(\mathbf{e}, \mathbf{g})$. Right. Applying RUV normalization increases power to detect statistically significant differences in gene expression (b,d), and allows separation of experimental groups (blue-green, green-red) of interest using three principal components* $(\mathbf{f}, \mathbf{h})$. *For 3-dimensional PCA plots, the first component represents experimental batch (correlation coefficient $>0.99$ ). As experimental batch is directly accounted for in the differential expression model, we excluded it here and considered PC 2-4 for visualization and the assessment of RUV normalization. Fig. S11. RUV normalization for analysis of homecage and trained wildtype mice RNAseq experiments. Left. Without applying RUV normalization, uncorrected P-values from the differential expression analysis are uniformly distributed and few genes are found to be statistically significant at false discovery rate (FDR) $<=0.05$ after multiple testing correction $(\mathbf{a}, \mathbf{c})$. RLE and PCA plots reveal traditional normalization approaches fail to allow separation of biologically meaningful groups using three principal components* $(\mathbf{e}, \mathbf{g})$. Right. Applying RUV normalization increases power to detect statistically significant differences in gene expression $(\mathbf{b}, \mathbf{d})$, and allows separation of experimental groups (blue-green, green-red) of interest using three principal components $(\mathbf{f}, \mathbf{h})$.

Additional file $\mathbf{2}$ : Table S1. List of Genes Differentially Expressed in $\mathrm{CBP}^{\mathrm{KI} / \mathrm{KIX}}$ mutants compared to wild-type littermates after spatial learning. Table S2. List of the upstream regulators of the DEGs in CBP $\mathrm{KII} / \mathrm{KIX}^{\mathrm{N}}$ mutants. Table S3. List of Genes Differentially Expressed in wildtype mice after spatial learning compared to homecage. Table S4. Positive controls for validation of differential gene expression analysis. Table S5. List of the upstream regulators of the DEGs in wild-type mice following learning. Table S6. High confidence (80\%) changes in homecage gene expression in CBP KII/KIX mice. Table S7. List of GPCR primers used to study gene expression.

\section{Acknowledgements}

\section{Not applicable.}

\section{Authors' contributions}

SC, CCA, ALB, and TA planned the experiments. SC performed the MWM experiments and RNA extraction. CCA performed the circadian experiments. EB and JJM performed the bioinformatics analysis of the RNA sequencing data. JDH performed the RNA extraction and analyzed the microarray data. MEG and MY performed the initial bioinformatics analysis of the MWM and FC RNA seq data. SGP performed the FC and extracted RNA. GSP helped in performing activity experiments. ASA helped in RNA extraction and dissection. SC, CCA, and $\mathrm{LCL}$ contributed to the data interpretation and wrote the manuscript with advice from ALB and TA. JCC and KPG provided advice in editing the manuscript. All authors read and approved the final manuscript.

\section{Funding}

This work was supported by the National Institute of Health R01 MH087463 and R01 MH 087463-08S1 to T. A.r Centre National de la Recherche Scientifique, the University of Strasbourg and the Indo-French Centre for the Promotion of Advanced Research (Grant \#4803-3 to A.-L. B). T. A. was also supported by the Roy J. Carver Chair in Neuroscience at the University of lowa. The funding agency had no role in the design of the study, data collection, analysis, or interpretation and no role in the writing of the manuscript.

\section{Availability of data and materials}

The datasets generated and/or analyzed during the current study are available in the NCBI's Gene Expression Omnibus repository, GEO Series accession GSE151681 (https://www.ncbi.nlm.nih.gov/geo/query/acc.cgi?acc=GSE151681). 


\section{Authors' information}

CCA's present address is: Department of Psychiatry and Behavioral Sciences, Stanford University, Stanford, California, USA.

SGP's present address is: DNA Electronics, San Diego, California, USA. JDH's present address is: Department of Cellular Neuroscience, Neurodegeneration, and Repair, Yale University, New Haven, Connecticut, USA.

\section{Ethics approval and consent to participate}

Not applicable.

\section{Consent for publication}

Not applicable.

\section{Competing interests}

The authors declare that they have no competing interests.

\section{Author details}

'Laboratoire de Neuroscience Cognitives et Adaptatives (LNCA), Université de Strasbourg, Strasbourg, France. 'LNCA, CNRS UMR 7364, Strasbourg, France. ${ }^{3}$ Department of Neuroscience and Pharmacology, lowa Neuroscience Institute, Carver College of Medicine, University of lowa, lowa City, lowa, USA. ${ }^{4}$ Neuroscience Graduate Group, University of Pennsylvania, Philadelphia, USA. ${ }^{5}$ Department of Biology, University of Pennsylvania, Philadelphia, PA, USA. ${ }^{6}$ Department of Psychiatry, Carver College of Medicine, University of lowa, lowa City, lowa, USA. ${ }^{7}$ Interdisciplinary Graduate Program in Genetics, University of lowa, lowa City, lowa, USA. ${ }^{8}$ Pharmacology Graduate Group, University of Pennsylvania, Philadelphia, USA. ${ }^{9}$ Department of Basic and Clinical Neuroscience, King's College London, London, UK. ${ }^{10}$ Department of Biomedical Engineering, College of Engineering, University of lowa, lowa City, lowa, USA. " 1 Department of Communication Sciences and Disorders, College of Liberal Arts and Sciences, University of lowa, lowa City, lowa, USA.

${ }^{12}$ lowa Institute of Human Genetics, University of lowa, lowa City, lowa, USA. ${ }^{13}$ Program in Neuroscience, Department of Biological Science, Florida State University, Tallahassee, FL, USA.

Received: 26 June 2020 Accepted: 1 October 2020

Published online: 29 October 2020

\section{References}

1. Sekeres MJ, Neve RL, Frankland PW, Josselyn SA. Dorsal hippocampal CREB is both necessary and sufficient for spatial memory. Learn Mem. 2010;17(6):280-3.

2. Barco A, Marie H. Genetic approaches to investigate the role of CREB in neuronal plasticity and memory. Mol Neurobiol. 2011;44(3):330-49.

3. Kandel ER. The molecular biology of memory: CAMP, PKA, CRE, CREB-1, CREB-2, and CPEB. Mol Brain. 2012;5:14.

4. Pittenger C, Huang YY, Paletzki RF, Bourtchouladze R, Scanlin H, Vronskaya S, Kandel ER. Reversible inhibition of CREB/ATF transcription factors in region CA1 of the dorsal hippocampus disrupts hippocampus-dependent spatial memory. Neuron. 2002;34(3):447-62.

5. Kida S, Serita T. Functional roles of CREB as a positive regulator in the formation and enhancement of memory. Brain Res Bull. 2014;105:17-24.

6. Viosca J, Malleret G, Bourtchouladze R, Benito E, Vronskava S, Kandel ER, Barco A. Chronic enhancement of CREB activity in the hippocampus interferes with the retrieval of spatial information. Learn Mem. 2009;16(3): 198-209.

7. Kelly MP. Cyclic nucleotide signaling changes associated with normal aging and age-related diseases of the brain. Cell Signal. 2018:42:281-91.

8. Aigbogun MS, Stellhorn R, Krasa H, Kostic D. Severity of memory impairment in the elderly: association with health care resource use and functional limitations in the United States. Alzheimers Dement (Amst). 2017:8:51-9.

9. Global Health and Aging. NIH Publication 2011, 11-7737.

10. Brown GC. Living too long: the current focus of medical research on increasing the quantity, rather than the quality, of life is damaging our health and harming the economy. EMBO Rep. 2015;16(2):137-41.

11. Alberini CM, Kandel ER. The regulation of transcription in memory consolidation. Cold Spring Harb Perspect Biol. 2014;7(1):a021741.

12. Mayr B, Montminy M. Transcriptional regulation by the phosphorylationdependent factor CREB. Nat Rev Mol Cell Biol. 2001;2(8):599-609.
13. Radhakrishnan I, Perez-Alvarado GC, Parker D, Dyson HJ, Montminy MR, Wright PE. Solution structure of the KIX domain of CBP bound to the transactivation domain of CREB: a model for activator:coactivator interactions. Cell. 1997;91(6):741-52.

14. Giese KP, Mizuno K. The roles of protein kinases in learning and memory. Learn Mem. 2013;20(10):540-52.

15. Goodman RH, Smolik S. CBP/p300 in cell growth, transformation, and development. Genes Dev. 2000;14(13):1553-77.

16. Vo N, Goodman RH. CREB-binding protein and p300 in transcriptional regulation. J Biol Chem. 2001;276(17):13505-8.

17. Kalkhoven E. CBP and p300: HATs for different occasions. Biochem Pharmacol. 2004;68(6):1145-55.

18. Dyson HJ, Wright PE. Role of intrinsic protein disorder in the function and interactions of the transcriptional coactivators CREB-binding protein (CBP) and p300. J Biol Chem. 2016;291(13):6714-22.

19. Wood MA, Attner MA, Oliveira AM, Brindle PK, Abel T. A transcription factorbinding domain of the coactivator CBP is essential for long-term memory and the expression of specific target genes. Learn Mem. 2006;13(5):609-17.

20. Haettig J, Stefanko DP, Multani ML, Figueroa DX, McQuown SC, Wood MA. HDAC inhibition modulates hippocampus-dependent long-term memory for object location in a CBP-dependent manner. Learn Mem. 2011;18(2):71-9.

21. Valor LM, Pulopulos MM, Jimenez-Minchan M, Olivares R, Lutz B, Barco A. Ablation of CBP in forebrain principal neurons causes modest memory and transcriptional defects and a dramatic reduction of histone acetylation but does not affect cell viability. J Neurosci. 2011;31(5):1652-63.

22. Oike Y, Takakura N, Hata A, Kaname T, Akizuki M, Yamaguchi Y, Yasue H, Araki K, Yamamura K, Suda T. Mice homozygous for a truncated form of CREB-binding protein exhibit defects in hematopoiesis and vasculoangiogenesis. Blood. 1999;93(9):2771-9.

23. Oike Y, Hata A, Mamiya T, Kaname T, Noda Y, Suzuki M, Yasue H, Nabeshima T, Araki K, Yamamura K. Truncated CBP protein leads to classical RubinsteinTaybi syndrome phenotypes in mice: implications for a dominant-negative mechanism. Hum Mol Genet. 1999;8(3):387-96.

24. Bourtchouladze R, Lidge R, Catapano R, Stanley J, Gossweiler S, Romashko D, Scott R, Tully T. A mouse model of Rubinstein-Taybi syndrome: defective long-term memory is ameliorated by inhibitors of phosphodiesterase 4 . Proc Natl Acad Sci U S A. 2003;100(18):10518-22.

25. Alarcon JM, Malleret G, Touzani K, Vronskaya S, Ishii S, Kandel ER, Barco A. Chromatin acetylation, memory, and LTP are impaired in CBP+/- mice: a model for the cognitive deficit in Rubinstein-Taybi syndrome and its amelioration. Neuron. 2004;42(6):947-59.

26. Korzus E, Rosenfeld MG, Mayford M. CBP histone acetyltransferase activity is a critical component of memory consolidation. Neuron. 2004;42(6):961-72.

27. Wood MA, Kaplan MP, Park A, Blanchard EJ, Oliveira AM, Lombardi TL, Abel T. Transgenic mice expressing a truncated form of CREB-binding protein (CBP) exhibit deficits in hippocampal synaptic plasticity and memory storage. Learn Mem. 2005;12(2):111-9.

28. Vieira PA, Korzus E. CBP-dependent memory consolidation in the prefrontal cortex supports object-location learning. Hippocampus. 2015;25(12): 1532-40.

29. Yiu AP, Rashid AJ, Josselyn SA. Increasing CREB function in the CA1 region of dorsal hippocampus rescues the spatial memory deficits in a mouse model of Alzheimer's disease. Neuropsychopharmacology. 2011;36(11):2169-86.

30. Chatterjee S, Mizar P, Cassel R, Neidl R, Selvi BR, Mohankrishna DV, Vedamurthy BM, Schneider A, Bousiges O, Mathis C, et al. A novel activator of CBP/p300 acetyltransferases promotes neurogenesis and extends memory duration in adult mice. J Neurosci. 2013;33(26):10698-712.

31. Chatterjee S, Cassel R, Schneider-Anthony A, Merienne K, Cosquer B, Tzeplaeff L, Halder Sinha S, Kumar M, Chaturbedy P, Eswaramoorthy M et al. Reinstating plasticity and memory in a tauopathy mouse model with an acetyltransferase activator. EMBO Mol Med. 2018;10(11):e8587.

32. Hervas-Corpion I, Guiretti D, Alcaraz-Iborra M, Olivares R, Campos-Caro A, Barco A, Valor LM. Early alteration of epigenetic-related transcription in Huntington's disease mouse models. Sci Rep. 2018;8(1):9925.

33. Giampa C, DeMarch Z, D'Angelo V, Morello M, Martorana A, Sancesario G, Bernardi G, Fusco FR. Striatal modulation of cAMP-response-elementbinding protein (CREB) after excitotoxic lesions: implications with neuronal vulnerability in Huntington's disease. Eur J Neurosci. 2006; 23(1):11-20.

34. Ettcheto M, Abad S, Petrov D, Pedros I, Busquets O, Sanchez-Lopez E, Casadesus G, Beas-Zarate C, Carro E, Auladell C, et al. Early preclinical 
changes in hippocampal CREB-binding protein expression in a mouse model of familial Alzheimer's disease. Mol Neurobiol. 2018;55(6):4885-95.

35. Bartolotti N, Segura L, Lazarov O. Diminished CRE-induced plasticity is linked to memory deficits in familial Alzheimer's disease mice. J Alzheimers Dis. 2016:50(2):477-89.

36. Schueller E, Paiva I, Blanc F, Wang XL, Cassel JC, Boutillier AL, Bousiges O. Dysregulation of histone acetylation pathways in hippocampus and frontal cortex of Alzheimer's disease patients. Eur Neuropsychopharmacol. Eur Neuropsychopharmacol. 2020;33:101-16.

37. Huang WC, Ju TK, Hung MC, Chen CC. Phosphorylation of CBP by IKKalpha promotes cell growth by switching the binding preference of CBP from p53 to NF-kappaB. Mol Cell. 2007;26(1):75-87.

38. Hosoda H, Kato K, Asano H, Ito M, Kato H, Iwamoto T, Suzuki A, Masushige S, Kida S. CBP/p300 is a cell type-specific modulator of CLOCK/BMAL1mediated transcription. Mol Brain. 2009;2:34

39. Takahata S, Ozaki T, Mimura J, Kikuchi Y, Sogawa K, Fujii-Kuriyama Y. Transactivation mechanisms of mouse clock transcription factors, mClock and mArnt3. Genes Cells. 2000;5(9):739-47.

40. Lee Y, Lee J, Kwon I, Nakajima Y, Ohmiya Y, Son GH, Lee KH, Kim K. Coactivation of the CLOCK-BMAL1 complex by CBP mediates resetting of the circadian clock. J Cell Sci. 2010;123(Pt 20):3547-57.

41. Kasper LH, Boussouar F, Ney PA, Jackson CW, Rehg J, van Deursen JM, Brindle PK. A transcription-factor-binding surface of coactivator p300 is required for haematopoiesis. Nature. 2002;419(6908):738-43.

42. Stefanko DP, Barrett RM, Ly AR, Reolon GK, Wood MA. Modulation of longterm memory for object recognition via HDAC inhibition. Proc Natl Acad Sci U S A. 2009;106(23):9447-52.

43. Thakur JK, Yadav A, Yadav G. Molecular recognition by the KIX domain and its role in gene regulation. Nucleic Acids Res. 2014;42(4):2112-25.

44. Barrett RM, Malvaez M, Kramar E, Matheos DP, Arrizon A, Cabrera SM, Lynch G, Greene RW, Wood MA. Hippocampal focal knockout of CBP affects specific histone modifications, long-term potentiation, and long-term memory. Neuropsychopharmacology. 2011;36(8):1545-56.

45. Vorhees CV, Williams MT. Morris water maze: procedures for assessing spatial and related forms of learning and memory. Nat Protoc. 2006;1(2):848-58.

46. Parker D, Ferreri K, Nakajima T, LaMorte VJ, Evans R, Koerber SC, Hoeger C, Montminy MR. Phosphorylation of CREB at Ser-133 induces complex formation with CREB-binding protein via a direct mechanism. Mol Cell Biol. 1996;16(2):694-703.

47. Parker D, Rivera M, Zor T, Henrion-Caude A, Radhakrishnan I, Kumar A Shapiro LH, Wright PE, Montminy M, Brindle PK. Role of secondary structure in discrimination between constitutive and inducible activators. Mol Cell Biol. 1999;19(8):5601-7.

48. Broadbent NJ, Squire LR, Clark RE. Spatial memory, recognition memory, and the hippocampus. Proc Natl Acad Sci U S A. 2004;101(40):14515-20.

49. Moser MB, Moser El, Forrest E, Andersen P, Morris RG. Spatial learning with a minislab in the dorsal hippocampus. Proc Natl Acad Sci U S A. 1995;92(21): 9697-701.

50. Fanselow MS, Dong HW. Are the dorsal and ventral hippocampus functionally distinct structures? Neuron. 2010;65(1):7-19.

51. Goshen I, Brodsky M, Prakash R, Wallace J, Gradinaru V, Ramakrishnan C, Deisseroth K. Dynamics of retrieval strategies for remote memories. Cell. 2011;147(3):678-89.

52. Bose DA, Donahue G, Reinberg D, Shiekhattar R, Bonasio R, Berger SL. RNA binding to CBP stimulates histone acetylation and transcription. Cell. 2017; 168(1-2):135-49 e122.

53. Gustafson $\mathrm{CL}$, Partch CL. Emerging models for the molecular basis of mammalian circadian timing. Biochemistry. 2015;54(2):134-49.

54. Gustafson CL, Parsley NC, Asimgil H, Lee HW, Ahlbach C, Michael AK, Xu H, Williams OL, Davis TL, Liu AC, et al. A slow conformational switch in the BMAL1 transactivation domain modulates circadian rhythms. Mol Cell. 2017; 66(4):447-57 e447.

55. Fernandez-Albert J, Lipinski M, Lopez-Cascales MT, Rowley MJ, MartinGonzalez AM, Del Blanco B, Corces VG, Barco A. Immediate and deferred epigenomic signatures of in vivo neuronal activation in mouse hippocampus. Nat Neurosci. 2019;22(10):1718-30.

56. Rawashdeh O, Parsons R, Maronde E. Clocking in time to gate memory processes: the circadian clock is part of the ins and outs of memory. Neural Plast. 2018;2018:6238989.

57. Rawashdeh O, Jilg A, Maronde E, Fahrenkrug J, Stehle JH. Period1 gates the circadian modulation of memory-relevant signaling in mouse hippocampus by regulating the nuclear shuttling of the CREB kinase pP90RSK. J Neurochem. 2016;138(5):731-45.

58. Kwapis JL, Alaghband Y, Kramar EA, Lopez AJ, Vogel Ciernia A, White AO, Shu G, Rhee D, Michael CM, Montellier E, et al. Epigenetic regulation of the circadian gene Per 1 contributes to age-related changes in hippocampal memory. Nat Commun. 2018;9(1):3323.

59. Rawashdeh O, Jilg A, Jedlicka P, Slawska J, Thomas L, Saade A, Schwarzacher SW, Stehle JH. PERIOD1 coordinates hippocampal rhythms and memory processing with daytime. Hippocampus. 2014;24(6):712-23.

60. Drapeau E, Montaron MF, Aguerre S, Abrous DN. Learning-induced survival of new neurons depends on the cognitive status of aged rats. J Neurosci. 2007;27(22):6037-44.

61. Martinez-Canabal A, Akers KG, Josselyn SA, Frankland PW. Age-dependent effects of hippocampal neurogenesis suppression on spatial learning. Hippocampus. 2013;23(1):66-74.

62. Stone SS, Teixeira CM, Devito LM, Zaslavsky K, Josselyn SA, Lozano AM, Frankland PW. Stimulation of entorhinal cortex promotes adult neurogenesis and facilitates spatial memory. J Neurosci. 2011;31(38): 13469-84.

63. De Cesare D, Sassone-Corsi P. Transcriptional regulation by cyclic AMPresponsive factors. Prog Nucleic Acid Res Mol Biol. 2000;64:343-69.

64. Shalev M, Aviram R, Adamovich Y, Kraut-Cohen J, Shamia T, Ben-Dor S, Golik $M$, Asher $G$. The PXDLS linear motif regulates circadian rhythmicity through protein-protein interactions. Nucleic Acids Res. 2014;42(19):11879-90.

65. Angelakos CC, Watson AJ, O'Brien WT, Krainock KS, Nickl-Jockschat T, Abel T. Hyperactivity and male-specific sleep deficits in the 16p11.2 deletion mouse model of autism. Autism Res. 2017;10(4):572-84.

66. Debruyne JP, Noton E, Lambert CM, Maywood ES, Weaver DR, Reppert SM. A clock shock: mouse CLOCK is not required for circadian oscillator function. Neuron. 2006:50(3):465-77.

67. Cermakian N, Monaco L, Pando MP, Dierich A, Sassone-Corsi P. Altered behavioral rhythms and clock gene expression in mice with a targeted mutation in the Period1 gene. EMBO J. 2001;20(15):3967-74.

68. Shearman LP, Jin X, Lee C, Reppert SM, Weaver DR. Targeted disruption of the mPer3 gene: subtle effects on circadian clock function. Mol Cell Biol. 2000;20(17):6269-75.

69. Preitner N, Damiola F, Lopez-Molina L, Zakany J, Duboule D, Albrecht U, Schibler U. The orphan nuclear receptor REV-ERBalpha controls circadian transcription within the positive limb of the mammalian circadian oscillator. Cell. 2002;110(2):251-60.

70. Lopez-Molina L, Conquet F, Dubois-Dauphin M, Schibler U. The DBP gene is expressed according to a circadian rhythm in the suprachiasmatic nucleus and influences circadian behavior. EMBO J. 1997;16(22):6762-71.

71. Sato TK, Panda S, Miraglia LJ, Reyes TM, Rudic RD, McNamara P, Naik KA, FitzGerald GA, Kay SA, Hogenesch JB. A functional genomics strategy reveals Rora as a component of the mammalian circadian clock. Neuron. 2004:43(4):527-37.

72. Andre E, Gawlas K, Becker-Andre M. A novel isoform of the orphan nuclear receptor RORbeta is specifically expressed in pineal gland and retina. Gene. 1998;216(2):277-83.

73. Dudley CA, Erbel-Sieler C, Estill SJ, Reick M, Franken P, Pitts S, McKnight SL Altered patterns of sleep and behavioral adaptability in NPAS2-deficient mice. Science. 2003;301(5631):379-83.

74. Ko CH, Takahashi JS: Molecular components of the mammalian circadian clock. Hum Mol Genet 2006, 15 Spec No 2:R271-277.

75. Jud C, Schmutz I, Hampp G, Oster H, Albrecht U. A guideline for analyzing circadian wheel-running behavior in rodents under different lighting conditions. Biol Proced Online. 2005;7:101-16.

76. Chen G, Zou X, Watanabe H, van Deursen JM, Shen J. CREB binding protein is required for both short-term and long-term memory formation. J Neurosci. 2010;30(39):13066-77.

77. Sharma N, Lopez DI, Nyborg JK. DNA binding and phosphorylation induce conformational alterations in the kinase-inducible domain of CREB. Implications for the mechanism of transcription function. J Biol Chem. 2007; 282(27):19872-83.

78. Montminy M. Transcriptional regulation by cyclic AMP. Annu Rev Biochem. 1997;66:807-22.

79. Sassone-Corsi P. Transcription factors responsive to CAMP. Annu Rev Cell Dev Biol. 1995;11:355-77.

80. Peixoto LL, Wimmer ME, Poplawski SG, Tudor JC, Kenworthy CA, Liu S, Mizuno K, Garcia BA, Zhang NR, Giese K, et al. Memory acquisition and 
retrieval impact different epigenetic processes that regulate gene expression. BMC Genomics. 2015;16(Suppl 5):S5.

81. Poplawski SG, Peixoto L, Porcari GS, Wimmer ME, McNally AG, Mizuno K, Giese KP, Chatterjee S, Koberstein JN, Risso D, et al. Contextual fear conditioning induces differential alternative splicing. Neurobiol Learn Mem. 2016;134(Pt B):221-35.

82. McNulty SE, Barrett RM, Vogel-Ciernia A, Malvaez M, Hernandez N, Davatolhagh MF, Matheos DP, Schiffman A, Wood MA. Differential roles for Nr4a1 and $\mathrm{Nr4a2}$ in object location vs. object recognition long-term memory. Learn Mem. 2012;19(12):588-92.

83. Hawk JD, Abel T. The role of NR4A transcription factors in memory formation. Brain Res Bull. 2011;85(1-2):21-9.

84. Bridi MS, Abel T. The NR4A orphan nuclear receptors mediate transcriptiondependent hippocampal synaptic plasticity. Neurobiol Learn Mem. 2013;105:151-8.

85. Bridi MS, Hawk JD, Chatterjee S, Safe S, Abel T. Pharmacological activators of the NR4A nuclear receptors enhance LTP in a CREB/CBP-dependent manner. Neuropsychopharmacology. 2017:42(6):1243-53.

86. Kwapis JL, Alaghband Y, Lopez AJ, Long JM, Li X, Shu G, Bodinayake KK, Matheos DP, Rapp PR, Wood MA. HDAC3-mediated repression of the Nr4a family contributes to age-related impairments in long-term memory. J Neurosci. 2019;39(25):4999-5009.

87. Chatterjee S, Walsh E, Yan A, Giese K, Safe S, Abel T. Pharmacological activation of Nr4A rescues age-associated memory decline. Neurobiol Aging. 2020;85:140-4.

88. Snider KH, Sullivan KA, Obrietan K. Circadian regulation of hippocampaldependent memory: circuits, synapses, and molecular mechanisms. Neural Plast. 2018:2018:7292540.

89. Eckel-Mahan KL, Phan T, Han S, Wang H, Chan GC, Scheiner ZS, Storm DR. Circadian oscillation of hippocampal MAPK activity and cAmp: implications for memory persistence. Nat Neurosci. 2008;11(9):1074-82.

90. Travnickova-Bendova Z, Cermakian N, Reppert SM, Sassone-Corsi P. Bimodal regulation of mPeriod promoters by CREB-dependent signaling and CLOCK BMAL1 activity. Proc Natl Acad Sci U S A. 2002;99(11):7728-33.

91. Tischkau SA, Mitchell JW, Tyan SH, Buchanan GF, Gillette MU. Ca2+/cAMP response element-binding protein (CREB)-dependent activation of Per1 is required for light-induced signaling in the suprachiasmatic nucleus circadian clock. J Biol Chem. 2003;278(2):718-23.

92. Garg A, Orru R, Ye W, Distler U, Chojnacki JE, Kohn M, Tenzer S, Sonnichsen C, Wolf E. Structural and mechanistic insights into the interaction of the circadian transcription factor BMAL1 with the KIX domain of the CREBbinding protein. J Biol Chem. 2019;294(45):16604-19.

93. Xu H, Gustafson CL, Sammons PJ, Khan SK, Parsley NC, Ramanathan C, Lee HW, Liu AC, Partch CL. Cryptochrome 1 regulates the circadian clock through dynamic interactions with the BMAL1 C terminus. Nat Struct Mol Biol. 2015;22(6):476-84.

94. Hung HC, Maurer C, Kay SA, Weber F. Circadian transcription depends on limiting amounts of the transcription co-activator nejire/CBP. J Biol Chem. 2007:282(43):31349-57.

95. Lim C, Lee J, Koo E, Choe J. Targeted inhibition of Pdplepsilon abolishes the circadian behavior of Drosophila melanogaster. Biochem Biophys Res Commun. 2007:364(2):294-300.

96. Lim C, Lee J, Choi C, Kim J, Doh E, Choe J. Functional role of CREB-binding protein in the circadian clock system of Drosophila melanogaster. Mol Cell Biol. 2007;27(13):4876-90.

97. Maurer C, Winter T, Chen S, Hung HC, Weber F. The CREB-binding protein affects the circadian regulation of behaviour. FEBS Lett. 2016;590(18):3213-20.

98. Jagannath A, Butler R, Godinho SIH, Couch Y, Brown LA, Vasudevan SR, Flanagan KC, Anthony D, Churchill GC, Wood MJA, et al. The CRTC1-SIK1 pathway regulates entrainment of the circadian clock. Cell. 2013;154(5):1100-11.

99. Sakamoto K, Norona FE, Alzate-Correa D, Scarberry D, Hoyt KR, Obrietan K. Clock and light regulation of the CREB coactivator CRTC1 in the suprachiasmatic circadian clock. J Neurosci. 2013;33(21):9021-7.

100. Ruby NF, Hwang CE, Wessells C, Fernandez F, Zhang P, Sapolsky R, Heller HC. Hippocampal-dependent learning requires a functional circadian system. Proc Natl Acad Sci U S A. 2008;105(40):15593-8.

101. Ruby NF, Fernandez F, Garrett A, Klima J, Zhang P, Sapolsky R, Heller HC. Spatial memory and long-term object recognition are impaired by circadian arrhythmia and restored by the GABAAAntagonist pentylenetetrazole. PLoS One. 2013:8(8):e72433.

102. Tomas Pereira I, Coletta CE, Perez EV, Kim DH, Gallagher M, Goldberg IG, Rapp PR. CREB-binding protein levels in the rat hippocampus fail to predict chronological or cognitive aging. Neurobiol Aging. 2013;34(3):832-44.
103. Ren X, Rizavi HS, Khan MA, Bhaumik R, Dwivedi Y, Pandey GN. Alteration of cyclic-AMP response element binding protein in the postmortem brain of subjects with bipolar disorder and schizophrenia. J Affect Disord. 2014;152154:326-33.

104. Rouaux C, Jokic N, Mbebi C, Boutillier S, Loeffler JP, Boutillier AL. Critical loss of CBP/p300 histone acetylase activity by caspase- 6 during neurodegeneration. EMBO J. 2003;22(24):6537-49.

105. Rouaux C, Loeffler JP, Boutillier AL. Targeting CREB-binding protein (CBP) loss of function as a therapeutic strategy in neurological disorders. Biochem Pharmacol. 2004;68(6):1157-64.

106. Caccamo A, Maldonado MA, Bokov AF, Majumder S, Oddo S. CBP gene transfer increases BDNF levels and ameliorates learning and memory deficits in a mouse model of Alzheimer's disease. Proc Natl Acad Sci U S A. 2010; 107(52):22687-92.

107. De Nobrega AK, Lyons LC. Aging and the clock: perspective from flies to humans. Eur J Neurosci. 2020;51(1):454-81.

108. Valentinuzzi VS, Scarbrough K, Takahashi JS, Turek FW. Effects of aging on the circadian rhythm of wheel-running activity in C57BL/6 mice. Am J Phys. 1997;273(6):R1957-64.

109. Mantovani S, Smith SS, Gordon R, O'Sullivan JD. An overview of sleep and circadian dysfunction in Parkinson's disease. J Sleep Res. 2018;27(3):e12673.

110. Musiek ES, Xiong DD, Holtzman DM. Sleep, circadian rhythms, and the pathogenesis of Alzheimer disease. Exp Mol Med. 2015;47:e148.

111. McKee CA, Lananna BV, Musiek ES. Circadian regulation of astrocyte function: implications for Alzheimer's disease. Cell Mol Life Sci. 2020;77(6):1049-58.

112. Leng Y, Musiek ES, Hu K, Cappuccio FP, Yaffe K. Association between circadian rhythms and neurodegenerative diseases. Lancet Neurol. 2019; 18(3):307-18.

113. Musiek ES, Holtzman DM. Mechanisms linking circadian clocks, sleep, and neurodegeneration. Science. 2016;354(6315):1004-8.

114. Musiek ES, Bhimasani M, Zangrilli MA, Morris JC, Holtzman DM, Ju YS. Circadian rest-activity pattern changes in aging and preclinical Alzheimer disease. JAMA Neurol. 2018;75(5):582-90.

115. Kontis V, Bennett JE, Mathers CD, Li G, Foreman K, Ezzati M. Future life expectancy in 35 industrialised countries: projections with a Bayesian model ensemble. Lancet. 2017;389(10076):1323-35.

116. Bousiges O, Vasconcelos AP, Neidl R, Cosquer B, Herbeaux K, Panteleeva I, Loeffler JP, Cassel JC, Boutillier AL. Spatial memory consolidation is associated with induction of several lysine-acetyltransferase (histone acetyltransferase) expression levels and $\mathrm{H} 2 \mathrm{~B} / \mathrm{H} 4$ acetylation-dependent transcriptional events in the rat hippocampus. Neuropsychopharmacology. 2010;35(13):2521-37.

117. Vecsey CG, Hawk JD, Lattal KM, Stein JM, Fabian SA, Attner MA, Cabrera SM, McDonough CB, Brindle PK, Abel T, et al. Histone deacetylase inhibitors enhance memory and synaptic plasticity via CREB:CBP-dependent transcriptional activation. J Neurosci. 2007;27(23):6128-40.

118. Gentleman RC, Carey VJ, Bates DM, Bolstad B, Dettling M, Dudoit S, Ellis B, Gautier L, Ge Y, Gentry J, et al. Bioconductor: open software development for computational biology and bioinformatics. Genome Biol. 2004;5(10):R80.

119. Kauffmann A, Gentleman R, Huber W. arrayQualityMetrics--a bioconductor package for quality assessment of microarray data. Bioinformatics. 2009; 25(3):415-6.

120. Dobin A, Davis CA, Schlesinger F, Drenkow J, Zaleski C, Jha S, Batut $P$, Chaisson M, Gingeras TR. STAR: ultrafast universal RNA-seq aligner. Bioinformatics. 2013;29(1):15-21.

121. Liao Y, Smyth GK, Shi W. featureCounts: an efficient general purpose program for assigning sequence reads to genomic features. Bioinformatics. 2014;30(7):923-30

122. Team RC. R: a language and environment for statistical computing. Vienna: R Foundation for Statistical Computing; 2019.

123. Risso D, Schwartz K, Sherlock G, Dudoit S. GC-content normalization for RNA-Seq data. BMC Bioinformatics. 2011;12:480.

124. Risso D, Ngai J, Speed TP, Dudoit S. Normalization of RNA-seq data using factor analysis of control genes or samples. Nat Biotechnol. 2014; 32(9):896-902.

125. Peixoto L, Risso D, Poplawski SG, Wimmer ME, Speed TP, Wood MA, Abel T. How data analysis affects power, reproducibility and biological insight of RNAseq studies in complex datasets. Nucleic Acids Res. 2015;43(16):7664-74.

126. Robinson MD, McCarthy DJ, Smyth GK. edgeR: a Bioconductor package for differential expression analysis of digital gene expression data. Bioinformatics. 2010;26(1):139-40. 
127. McCarthy DJ, Chen Y, Smyth GK. Differential expression analysis of multifactor RNA-Seq experiments with respect to biological variation. Nucleic Acids Res. 2012;40(10):4288-97.

128. Plaisier SB, Taschereau R, Wong JA, Graeber TG. Rank-rank hypergeometric overlap: identification of statistically significant overlap between geneexpression signatures. Nucleic Acids Res. 2010;38(17):e169.

129. Yu G, Wang LG, Han Y, He QY. clusterProfiler: an R package for comparing biological themes among gene clusters. OMICS. 2012;16(5):284-7.

130. Lorsch ZS, Loh YE, Purushothaman I, Walker DM, Parise EM, Salery M, Cahill ME, Hodes GE, Pfau ML, Kronman H, et al. Estrogen receptor alpha drives pro-resilient transcription in mouse models of depression. Nat Commun. 2018;9(1):1116

131. Angelakos CC, Tudor JC, Ferri SL, Jongens TA, Abel T. Home-cage hypoactivity in mouse genetic models of autism spectrum disorder. Neurobiol Learn Mem. 2019;165:107000.

\section{Publisher's Note}

Springer Nature remains neutral with regard to jurisdictional claims in published maps and institutional affiliations.

Ready to submit your research? Choose BMC and benefit from:

- fast, convenient online submission

- thorough peer review by experienced researchers in your field

- rapid publication on acceptance

- support for research data, including large and complex data types

- gold Open Access which fosters wider collaboration and increased citations

- maximum visibility for your research: over $100 \mathrm{M}$ website views per year

At BMC, research is always in progress.

Learn more biomedcentral.com/submissions 